\title{
Habitat complexity and bottom fauna composition at different scales on the continental shelf and slope of northern Norway
}

\author{
L. Buhl-Mortensen • P. Buhl-Mortensen • \\ M. F. J. Dolan · J. Dannheim • V. Bellec • \\ B. Holte
}

Received: 18 April 2011/Accepted: 23 December 2011/Published online: 16 February 2012

(C) Springer Science+Business Media B.V. 2012

\begin{abstract}
The MAREANO (Marine AREA database for NOrwegian coast and sea areas) mapping programme includes acquisition of multibeam bathymetry and backscatter data together with a comprehensive, integrated biological and geological sampling programme. Equipment used includes underwater video, box corer, grab, epibenthic sled and beam trawl. Habitat maps are produced by combining information on landscapes, landscape elements, sediment types and biological communities. Video observations provide information about the megafauna diversity of large $(>1 \mathrm{~cm})$ epifauna and bottom types, whilst bottom samples describe the composition of epifauna, hyperfauna (crustaceans living in the upper part of the
\end{abstract}

Electronic supplementary material The online version of this article (doi:10.1007/s10750-011-0988-6) contains supplementary material, which is available to authorized users.

Guest editors: K. E. Kovalenko \& S. M. Thomaz /

The importance of habitat complexity in waterscapes

L. Buhl-Mortensen ( $₫) \cdot$ P. Buhl-Mortensen · B. Holte

Institute of Marine Research, Bergen, Norway

e-mail: Lenebu@imr.no

M. F. J. Dolan · V. Bellec

Geological Survey of Norway, Trondheim, Norway

J. Dannheim

Alfred Wegener Institute, Bremerhaven, Germany sediment and/or swimming just above the substratum) and infauna, and sediment composition. In this study, two biological data sets are used to study fauna response to environmental heterogeneity at two different spatial scales: (1) broad scale, megahabitat (1-10s km), based on information about megafauna taxa observed during video surveys in the Nordland/ Troms area, (2) fine scale, mesohabitat (10s m-1 km), based on information about species composition documented with video records and bottom sampling gear from the bank "Tromsøflaket". In general, the highest diversity is found on bottoms with mixed substrates indicating that substratum heterogeneity is very important for the biodiversity at both scales. The number of taxa shows a maximum at depths between 200 and $700 \mathrm{~m}$ followed by a gradual decrease down to 2,200 $\mathrm{m}$. At the broad scale, multibeam data provides a variety of terrain variables that indicate environmental variation (e.g. exposure to currents, interpreted substrates). This analysis identifies six fauna groups associated to specific landscape elements. Diversity of megafauna shows a strong correlation with number of bottom types occurring along video transects. It is highest at the shelf break and decreased with depth on the slope in parallel with a decrease in habitat heterogeneity and temperature. At a fine scale, six biotopes are identified based on megafauna composition with habitat characteristics ranging from homogenous muddy bottom, biotope 1 , to the most heterogeneous bottom with $>20 \%$ rocks and several bottom types present in biotope 6 . The macrofauna 
sampled is used for description of the whole benthic community, including diversity, biomass and production, related to these six biotopes. The variation in percentage cover of substrate types and in particular the cover of hard substrates demonstrate to be a good proxy for the benthic community composition (megaand macrofauna) and its diversity.

Keywords Benthic heterogeneity - Marine landscape $\cdot$ Scale of diversity $\cdot$ Benthic production . Biomass · Mapping · Video-survey

\section{Introduction}

What are the relationships between the physical environment, species diversity and biological production? This is one of the questions addressed by the MAREANO programme (Marine AREA database for NOrwegian coast and sea areas, www.mareano.no). Through the MAREANO programme the Norwegian government will produce maps of the seabed off Norway that can be used for management purposes. Mapping started in 2005 in the southern Barents Sea and by 2020, major parts of the Norwegian zone of the Barents Sea will be mapped (Fig. 1). The main goal is to obtain the information necessary to regulate human activities. Habitat maps are important tool for managing spatial conflicts between conservation of biodiversity and marine services and goods such as fishing and petroleum activities. The area mapped covers a variety of contrasting marine landscapes and landscape elements (e.g. banks, troughs [marine valleys], ridges and moraines, canyons, large sand waves and ripple fields, cold seeps, pockmarks and coral reefs) (Thorsnes et al., 2009; Buhl-Mortensen et al., 2012) at depths ranging from 40 to $2,200 \mathrm{~m}$. Over this depth range, different biological communities occurs that are limited bathymetrically to certain depth zones and water masses (Fig. 2). Bett (2001) has defined bathymetric zones from the shelf to the deep sea. The Shetland continental shelf (120-200 m depth) is described as having a variable cover of sand overlying a gravel substrate. A sediment wave zone (approximately $200-850 \mathrm{~m}$ depth) with long wavelength sediment waves occurs above a soft sediment zone (approximately 850-1,000 m depth). Below 1,000 m, the seabed is in general relatively featureless, except for in canyons (Buhl-Mortensen et al., 2010).

The concept of marine landscapes is a broad-scale classification of the marine environment based on geophysical features. It was first developed for Canadian waters by Roff \& Taylor (2000). Roff \& Taylor (2000) developed a classification system based on environmental factors such as water temperature,

Fig. 1 Areas mapped by MAREANO off northern Norway between 2005 and 2009. Data from the area "Tromsøflaket" are used in the fine scale analysis and data from the "Nordland/Troms" area in the broad-scale megafauna analysis

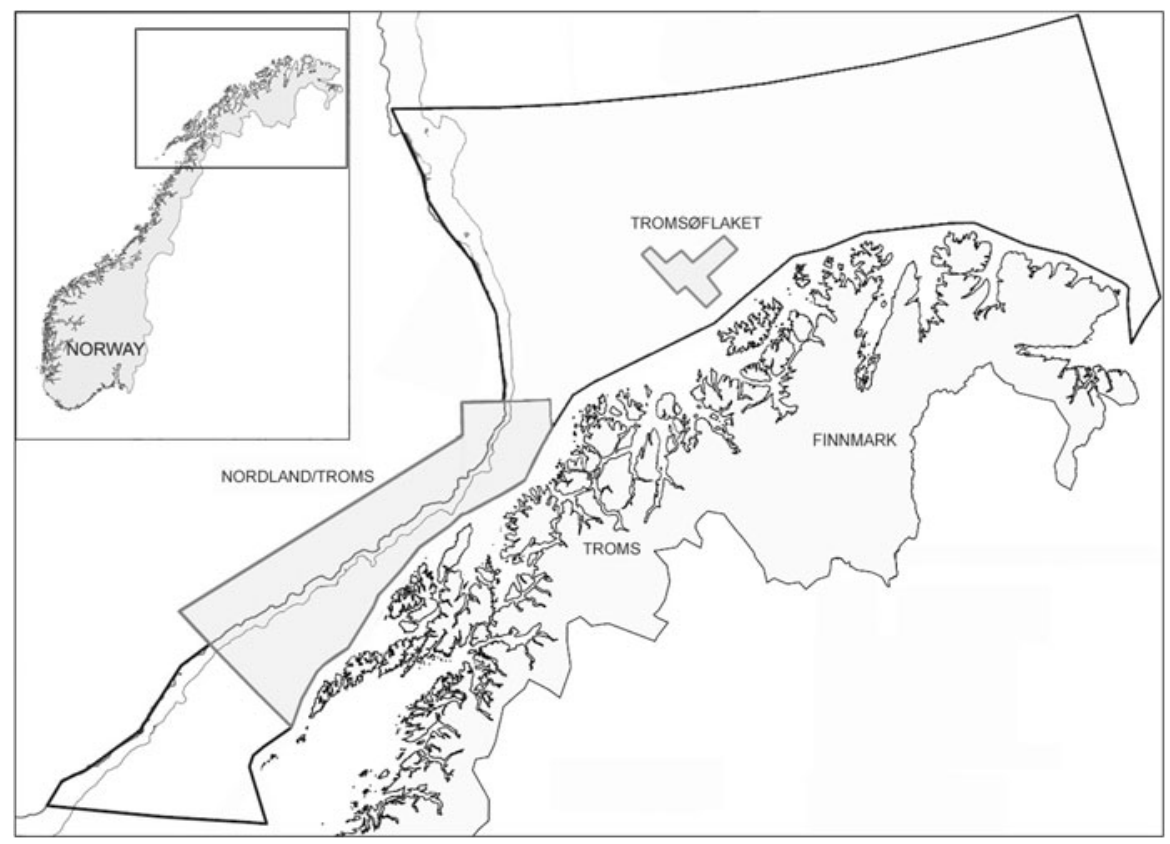


Fig. 2 Examples of different habitats and landscapes with some dominant organisms on the continental margin off Andøya Island in "Nordland". "Hola" is an example of a trough with strong currents. Here, 330 Lophelia reefs and a gas seep producing carbonate crusts and bacteria mats have been found

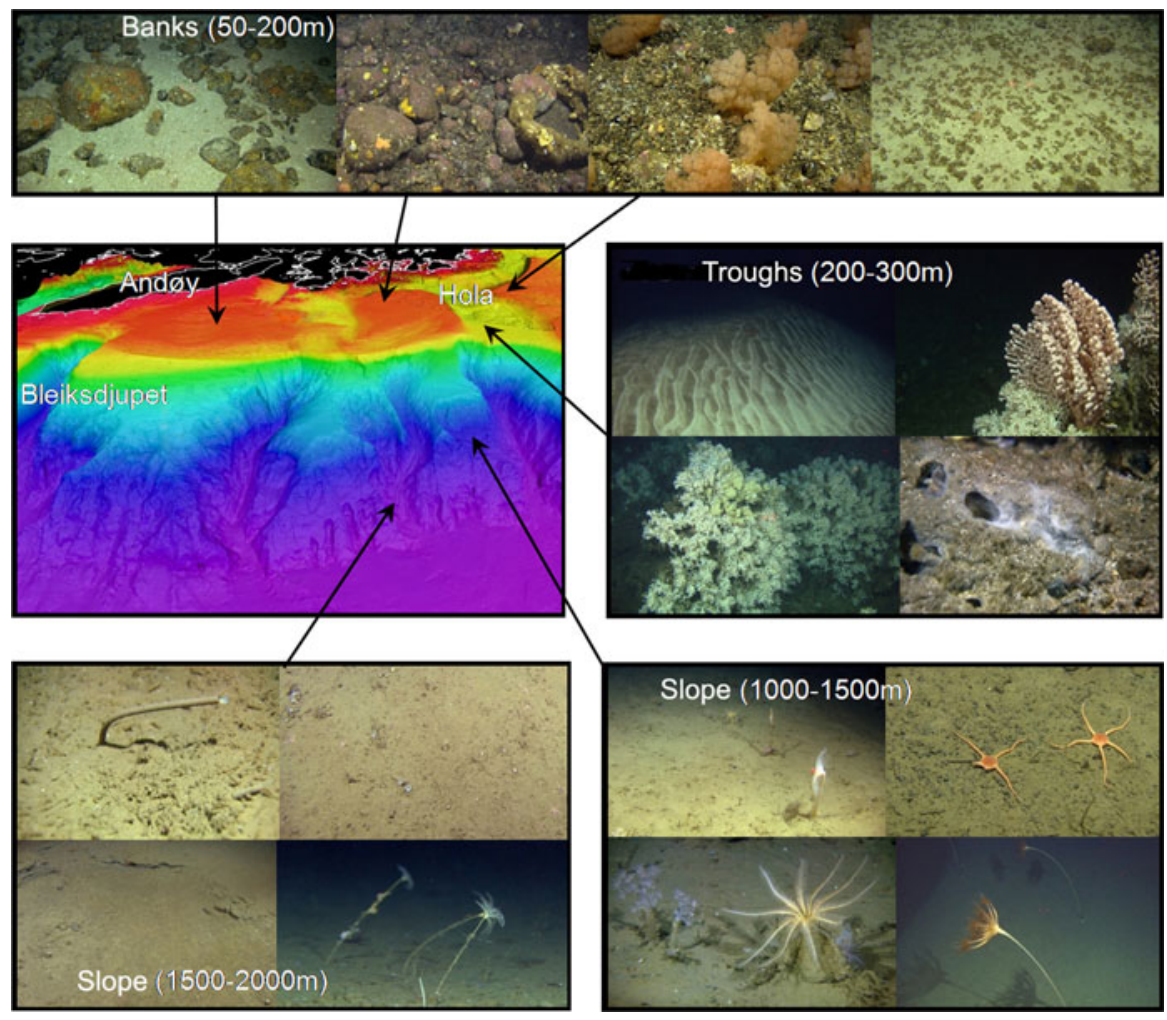

depth/light penetration, substratum type, exposure and slope. They termed the classes 'seascapes'. Currently, the term 'marine landscapes' is commonly used (see Golding et al., 2004). This level represents an intermediate scale between regional seas and habitats.

There are several approaches to marine landscape and habitat mapping. Greene et al. (1999) provide a classification scheme for deep-seafloor habitats where the issue of scale is dealt with in a hierarchy of classes. A similar hierarchical approach has been applied in the EUropean Nature Information System (EUNIS) (Davies et al., 2004). Both classification systems take into account the biological components of the habitat classes. However, whereas the classification scheme by Greene et al. (1999) use the biological components as modifiers of geological and geomorphological features at an intermediate scale (macro and mesohabitats), (10-1,000 m), the EUNIS classification emphasises taxonomic composition at the finer scale classification levels. Here we are studying fauna pattern at mega (1-10s km) and meso (10s m-1 km) scale as defined by Greene et al. (1999).

To understand marine ecosystems and to manage them in a sound way, a comprehensive knowledge on the distribution of species and communities is indispensible. Without this basis, we will not be able to detect changes to the ecosystem or monitor effects of any marine sanctuaries that may be designated. Conservation programmes often use biodiversity as a major criterion for identifying priority regions and this has led to marine biodiversity and its conservation receiving substantial attention in recent years. It is well established that the quantification of diversity is not straight forward (see Magurran, 2004).

Different sampling gears are designed to document different parts of the bottom community, e.g. grabs are used for infauna sampling and epi-benthic sleds to capturing motile near bottom crustacean (Bergman et al., 2009). The different samplers do not work equally well on all bottom types and terrains and, in addition, the area they cover differs. Thus, it is not possible to provide diversity information for all major fauna components and habitat with a gear that sample in the same manner and functions regardless of substratum.

The MAREANO mapping programme applies a wide set of sampling techniques to provide the best 
possible picture of the bottom fauna diversity in different environments on the continental shelf and slope of the Norwegian and Barents Sea. This provides unique opportunity to investigate the relation between: species richness of infauna, epifauna and hyperbenthos (crustaceans living in the upper part of the sediment or swimming just above the substratum) and different habitats; diversity and certain sediment descriptors; between productivity/production and diversity; and how functional group composition relates to diversity.

The habitat-diversity (heterogeneity) hypothesis states that an increase in habitat heterogeneity leads to an increase in species diversity (Whittaker et al., 2001 and for a review Tews et al., 2004). Habitat heterogeneity occur at all spatial scales used for habitat description. Etter \& Grassle (1992) show that variation in species diversity has a positive correlation with the heterogeneity of sediment grain size across a wide variety of spatial scales.

Habitat heterogeneity is here expressed as substrate variability and by topographic descriptors. At an intermediate scale, topographic variation (e.g. roughness and slope) represent a wider context where similar substrate types may differ in species diversity and composition depending on the type of landscape element (features such as iceberg ploughmarks and large sand waves).

Organisms relate differently to their environment whether due to mobility, size or resource specialization and their distribution patterns and response to environmental factors and patchiness of these factors will differ (Tews et al., 2004). It is well known that different taxonomic groups experiences and uses their surrounding environment differently (Tews et al., 2004). In this publication, we explore the relationships between benthic biodiversity, environmental factors and habitat heterogeneity on two scales:

- The broad, megascale, analysis will test if there is a landscape or landscape element specific fauna composition. This scale (1-10s km) includes landscape elements where we based on video documentation of megafauna to investigate if there is a fauna pattern that relates to these larger features that un-doughtily represents several habitats.

- The fine, mesoscale, analysis is used to study how biotopes are related to the patchy environment of a bank and the variability in response of different bottom fauna groups. At this scale $(10 \mathrm{~s} \mathrm{~m}-1 \mathrm{~km})$, we compare patterns in environmental setting with patterns in fauna composition of all major benthic fauna groups: Epifauna, hyperfauna, infauna from macro to megafauna in size (1 mm-cm's).

For this approach, we use two biological data sets: (1) broad-scale information on taxa distribution based on video surveys in the Nordland/Troms area and (2) fine scale species composition, including diversity, biomass and production, documented with a suite of and bottom sampling gear together with video records from the bank area named 'Tromsøflaket'.

\section{Study area}

The study site presented here comprises an area of $37,000 \mathrm{~km}^{2}$ off the counties Finnmark, Troms and Nordland in northern Norway (Fig. 1). This offshore area is commercially important for fisheries and potential exploitation of hydrocarbon. The area has a varied seabed topography including large low-relief areas and steep areas of sloping terrain. Water depth ranges from around $40 \mathrm{~m}$ on the banks down to $3,000 \mathrm{~m}$ on the deep-sea plain of the Norwegian Sea. The oceanography of the area is influenced by four major water masses (Hansen \& Østerhus, 2000). The northward flowing Norwegian Coastal Current comprises the low salinity Norwegian coastal water (NCW) with variable temperature. This water overlies the Norwegian Atlantic current (NAC) (with Norwegian Atlantic water, NAW) like a wedge thickest towards the coast. The NAW extends down to about $500-600 \mathrm{~m}$ and is part of the relatively warm and saline North Atlantic current. Below this depth, two cold water masses occur: the Norwegian Sea Arctic intermediate water (NSAIW) and the Norwegian Sea deep water (NSDW). NSAIW has a temperature range between -0.5 and $0.5^{\circ} \mathrm{C}$, whereas the NSDW typically shows a temperature range between -0.5 and $-1.1^{\circ} \mathrm{C}$. The interface between these two water masses typically occurs at around 1,300 $\mathrm{m}$ off the Norwegian coast in the Norwegian Sea. Figure 3 shows a temperature depth profile typical for the study area. 


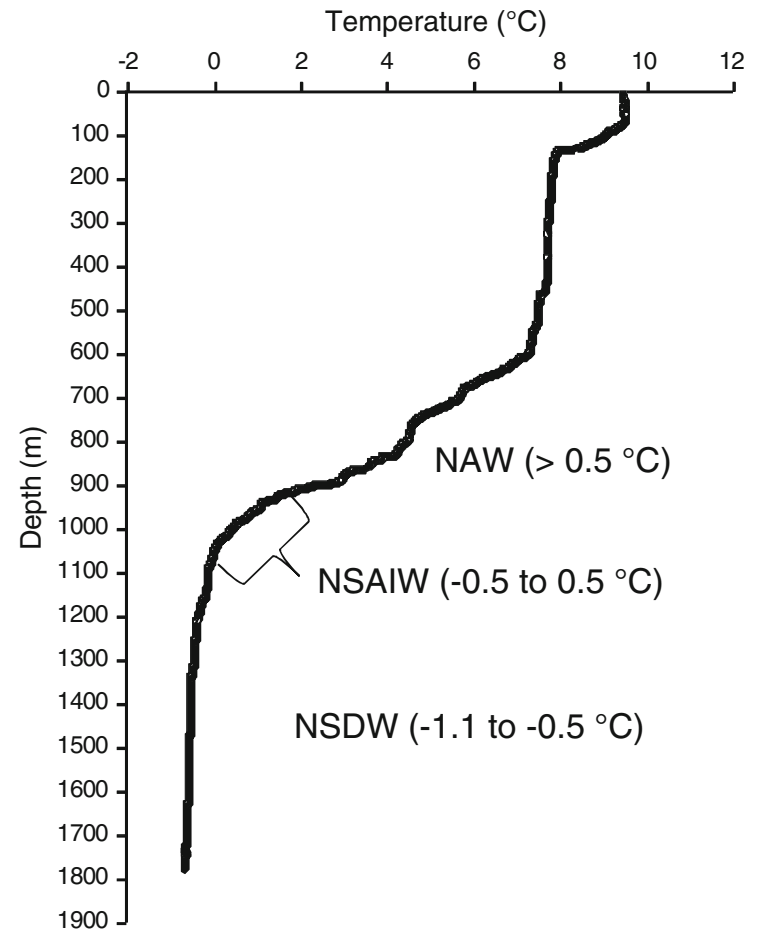

Fig. 3 General temperature profile with the different water masses influencing the bottom fauna in the two study areas indicated. On the "Tromsøflaket" used for the fine scale analysis at $140-450 \mathrm{~m}$ depth the NAW prevails and temperature range is $4-8^{\circ} \mathrm{C}$. In the Nordland area were the study covers depth from 200 to 2,200 $\mathrm{m}$ three main water masse prevail the upper NAW and below $600-700 \mathrm{~m}$ the NSAIW with 0.5 to $-0.5^{\circ} \mathrm{C}$ and below the NSDW with a constant negative temperature

\section{Material and methods}

Results from bottom topography, sediment and fauna mapping from four cruises (one in 2006 and 2007, and two cruises in 2008) that was part of the MAREANO programme were used in this study.

Bathymetry and sediment mapping

The study areas were mapped during a series of surveys using Kongsberg EM1002 $(95 \mathrm{kHz})$ or EM710 (70-100 kHz) multibeam echosounders. Bathymetry and backscatter data were acquired during each survey with sufficient density to allow $5 \mathrm{~m}$ raster grids to be made in all areas above $1,000 \mathrm{~m}$ water depth. These data were provided by the Norwegian Hydrographic Service in advance of the sampling surveys. Bathymetry data reveal the morphology of the seafloor whilst backscatter data give an indication of the properties of the seabed. Acoustic backscatter responds to several properties of the seabed (texture/ hardness/compactness, etc.) that, together with ground-truth samples, can be used to infer surficial sediment type. Based on the multibeam information, stations for documentation of fauna and bottom substratum were selected to ensure representative sampling of habitats likely to be different. The available habitat characteristics were: composition of sediment (where sampling was possible), percentage cover of sediment types from video, multibeam data providing information about seabed slope, rugosity, bathymetric position index (BPI) (bottom curvature) and backscatter intensity.

\section{Biotope identification and description}

Broad-scale (1-10s km) analysis of landscape and landscape elements is based on the information on bottom types and taxa from video surveys (164 transects, $700 \mathrm{~m}$ in length) in the high relief Nordland/Troms area (Fig. 4) covering an area of $30,000 \mathrm{~km}^{2}$ and a depth gradient of $40-2,000 \mathrm{~m}$ contrasting landscapes and landscape elements such as canyons, coral reefs, troughs and banks.

Landscapes and landscape elements were defined by Mortensen et al. (2009a) based on the detailed bathymetry maps produced from the multibeam data and additional information about the general hydrography (transition zone between warm NAW and cold water NSDW). The continental slope was divided into an upper (from the continental shelf break down to $700 \mathrm{~m}$ depth) and a lower part (>700 m depth). The ten landscape and landscape element units used for comparison are listed in Table 1.

During the two cruises in 2008, observations of bottom types and species of higher level taxa and sediment composition were recorded during field operations, enabling quick results, however, with less taxonomic and spatial resolution than the more labourintense play-back analyses used by Mortensen et al. (2009b). These real-time observations of the seabed using the video camera were made at 164 locations during two MAREANO cruises in 2008 with R/V. G.O. SARS. The occurrence of ten different bottom types (mud, sandy mud, sand, gravelly sand, sandy gravel, gravel, boulder, bedrock, coral reef and consolidated sediment) and megafauna organisms was recorded 
Fig. 4 Nordland/Troms study area. A Detailed bathymetry map showing the location of 164 video transects where bottom types and taxa were recorded by video in the field. This data set was used for a broad-scale approach for characterization of biotopes. B Distribution of landscapes and landscape elements defined by Mortensen et al. (2009a)
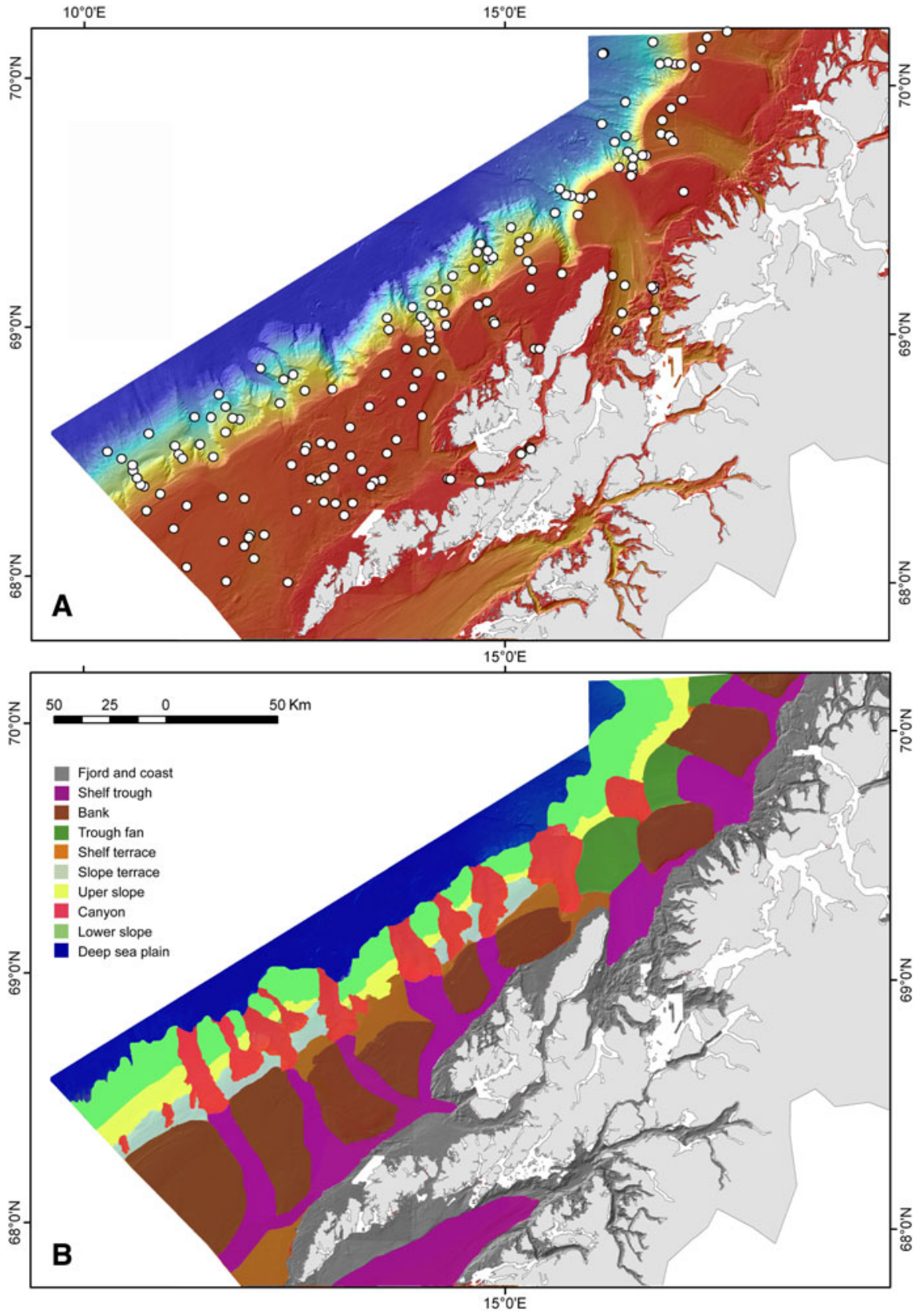

using the event logging software 'Campod Logger' from the Institute of Marine Research. The method for using this software in a standardised way is described by Mortensen et al. (2009a). Each taxon was recorded upon first occurrence within each video transect sequence. Relative composition of bottom substrates was calculated as the frequency of occurrence for each video transect. This technique provides a table of navigation data along with bottom type and records of occurrence of taxa for each video transect.

\section{Analysis of megafauna}

In order to identify species groups and the environmental variables that can be related to the landscape/ landscape elements, detrended correspondence 
Table 1 Ten landscape and landscape element units at different levels of classification based on broad-scale seabed topography and general distribution of water masses (from Mortensen et al., 2009a)

\begin{tabular}{|c|c|c|}
\hline & $\begin{array}{l}\text { Name of landscape/ } \\
\text { landscape element }\end{array}$ & Description \\
\hline (1) & Fjord and coast & $\begin{array}{l}\text { Varied topography, with not only frequent occurrence of exposed bedrock, but also muddy level } \\
\text { basins. This landscape is influenced by both NCW and North Atlantic Water }\end{array}$ \\
\hline (2) & Bank & $\begin{array}{l}\text { Glacial sediments dominate large parts of the banks and moraine ridges are also found. The banks } \\
\text { are separated by troughs crossing the shelf commonly connected with fjords. Large parts of the } \\
\text { banks have been heavily incised by iceberg ploughmarks (Bellec et al. 2008). }\end{array}$ \\
\hline (3) & Shelf terrace & $\begin{array}{l}\text { Five locations represent terraces on the shelf. These are relatively level areas at depths between the } \\
\text { shelf troughs and the banks. Within the study area this landscape mainly occurs between the shelf } \\
\text { break and the banks }\end{array}$ \\
\hline (4) & Shelf trough & $\begin{array}{l}\text { Troughs were formed by erosion from ice flow during glaciations. The shelf troughs separate the } \\
\text { banks and are often connected to fjords. The environment is variable with complex current } \\
\text { patterns and occurrence of both sedimentation and erosion areas }\end{array}$ \\
\hline$(5)$ & Trough fan & $\begin{array}{l}\text { Fans of sediments in the outer part of shelf troughs have been formed where the material } \\
\text { transported by the ice reached the shelf break. This landscape differs from the connected troughs } \\
\text { by being more exposed to the NAC }\end{array}$ \\
\hline (6) & Slope terrace & $\begin{array}{l}\text { Four locations occur in level areas below the shelf break. We termed this feature slope terrace. This } \\
\text { landscape is part of the larger slope landscape complex which includes smooth slope, canyons and } \\
\text { slide areas }\end{array}$ \\
\hline (7) & Upper slope & This landscape represents smoothly sloping seabed down to $700 \mathrm{~m}$, above the cold NSAIW \\
\hline (8) & Canyon & $\begin{array}{l}\text { Canyons are valleys, or incisions in the continental slope comprising a fractural branching structure } \\
\text { of smaller erosion channels meeting a central valley termed thalweg. The canyons often have } \\
\text { areas where submarine slides have changed the shape of the erosion channels. The canyons cover } \\
\text { water depths ranging from the shelf break down to the deep-sea plain, having a variable } \\
\text { hydrography with both the warm NAW, and the cold NSAIW and NSDW }\end{array}$ \\
\hline (9) & Lower slope & $\begin{array}{l}\text { This landscape has a relatively smooth sloping seabed similar to the upper slope, but is } \\
\text { characterised by the cold NSDW and NSAIW below the NAW, at around } 700 \mathrm{~m} \text { depth. This } \\
\text { landscape extends down to the deep-sea plain at around } 2,400 \mathrm{~m} \text { depth }\end{array}$ \\
\hline$(10)$ & Deep-sea plain & $\begin{array}{l}\text { The deep-sea plain is a level muddy seabed occurring typically below } 2,400 \mathrm{~m} \text { in the southern part } \\
\text { of the study area and shallower in the northern part. Only one location was represented in the } \\
\text { study area }\end{array}$ \\
\hline
\end{tabular}

analysis (DCA) was applied (using the software PCOrd), based on taxonomic composition and relative abundance. Only species occurring in three or more of the video transects were included which allowed 192 out of 377 taxa to be utilized for the broad-scale analysis. The video transects used for the broad-scale analyses reflect species composition accumulated over a distance of $700 \mathrm{~m}$, which we believe is an adequate scale for investigating patterns at a landscape scale.

Fine scale $(10 \mathrm{~s} \mathrm{~m}-1 \mathrm{~km})$ analysis of bottom fauna composition was based on video records (48 transects, $1,000 \mathrm{~m}$ in length) and a suite of bottom sampling gear (van Veen grab, beam trawl, and hyperbenthic sled) (62 samples in total) from a well defined bank area $\left(7,000 \mathrm{~km}^{2}\right)$ named 'Tromsøflaket' (Fig. 5) covering depths from 90 to $450 \mathrm{~m}$ including areas with pockmarks and moraine ridges. Terrain analysis was conducted on multibeam data and video transects were used to document sediment composition and large epifauna ( $>1 \mathrm{~cm}$ in size).

Faunal analyses were conducted on 48 video transects from the Tromsøflaket area (recorded on high definition format: HD-DVC pro format). During transects, each $1 \mathrm{~km}$ long, "CAMPOD" was towed behind the survey vessel at a speed of 0.7 knots and controlled by a winch operator providing a nearconstant altitude of $1.5 \mathrm{~m}$ above the seabed. Geopositioning for the video data was provided by a hydroacoustic positioning system (Simrad HIPAP and Eiva Navipac software) with a transponder mounted on 'CAMPOD', giving a position accurate to $2 \%$ of water depth. In all, 48 video records were analysed in detail initially using sequences $30 \mathrm{~s}$ long (average length $12 \mathrm{~m}$ ). Distances were calculated from recorded positions, and the field width was estimated from the recorded altitude (acoustic 


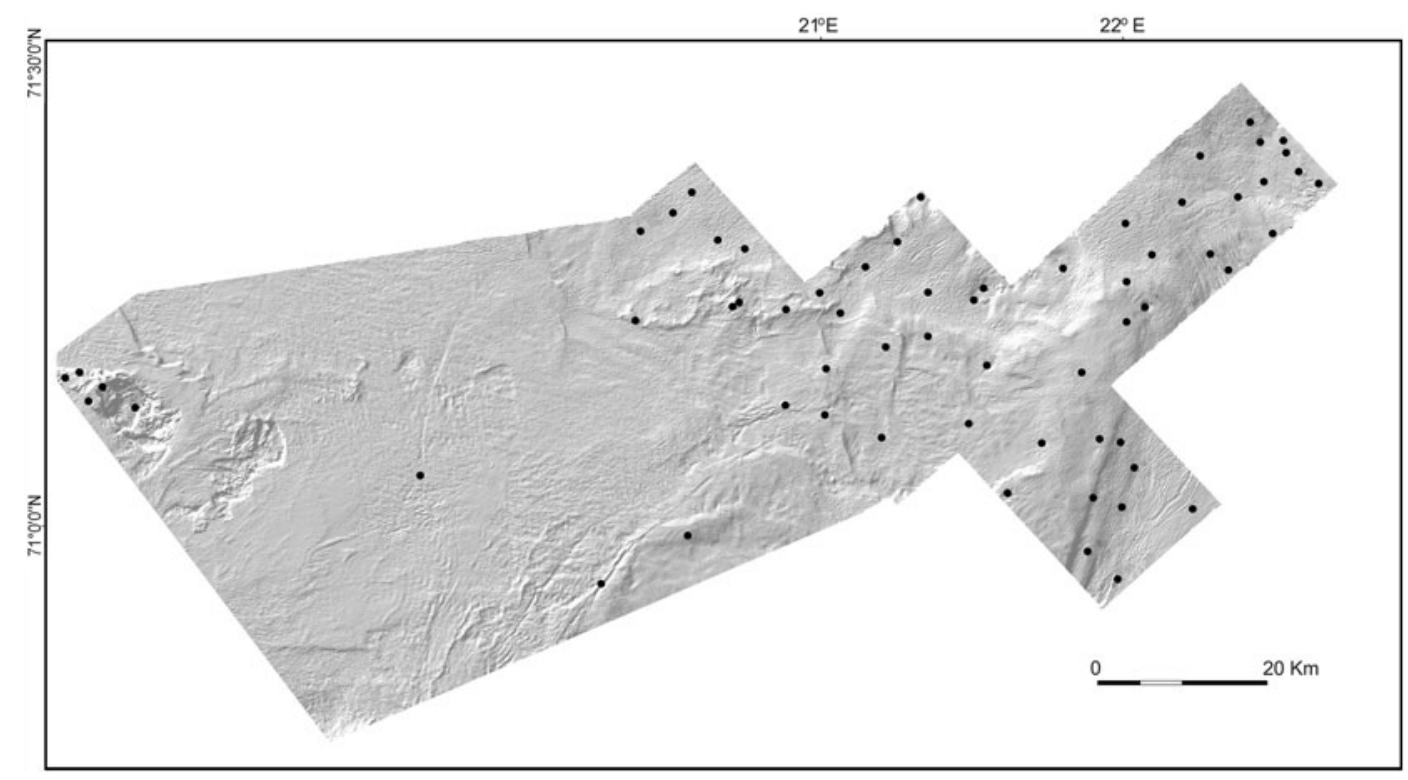

Fig. 5 Map (shaded relief) of the area "Tromsøflaket" with position of station. This data set was used for the fine-scale approach for characterization of biotopes and analysing the relation between habitat heterogeneity and fauna composition

altimeter) converted to field width based on the relationship between measurements made using a laser scale and the height above the seabed. All organisms were identified to the lowest possible taxon and counted, or quantified as $\%$ seabed coverage following the method described by Mortensen \& BuhlMortensen (2005). To standardize the sample size, the 30 -s sequences were pooled into distances of $200 \mathrm{~m}$. After an initial analysis of $50 \mathrm{~m}$ long sequences, $200 \mathrm{~m}$ was found to reveal the same patterns and represented a more convenient scale compared to time consuming processes related to computing of terrain variables and processing of video records. Abundance data (the number of organisms counted divided by the area observed) for solitary organisms were standardised as the number of individuals per $100 \mathrm{~m}^{2}$, and used for identifying habitat types for Tromsøflaket based on detailed post-cruise analyses (Mortensen et al., 2009b; Dolan et al., 2009). In order to identify species groups and the environmental variables that determine these groupings, DCA was applied (using the software PC-Ord) (Fig. 6). Only species occurring in three or more of the video transects were included which allowed 99 out of 195 taxa to be utilized for the fine scale analysis.

On the eastern part of Tromsøflaket six biotopes were identified based on video information of megafauna. Species typical (common and abundant) of each biotope are listed below (identified from video analysis and earlier presented by Mortensen et al., 2009b):

(1) Fine grained mud in shelf basins. Typical species: Pelosina arborescens (Foraminifera) and Asbestopluma pennatula (Porifera).

(2) Sandy mud in areas with iceberg ploughmarks. Typical species: various large sponges such as Geodia spp. (Porifera).

(3) Sandy sediments in level areas. Typical species: Ceramaster granularis (Asteroidea) and Stichopus tremulus (Holothuroidae).

(4) Gravelly sand on gently sloping seabed. Typical species: Stylocordyla borealis (Porifera) and Aphrodite sp. (Polychaeta).

(5) Sandy gravel with cobble in areas with iceberg ploughmarks. Typical species: Phakellia sp. and Axinella sp. (Porifera).

(6) Sandy gravel with cobbles and boulders on morainic ridges. Typical species: Polymastia sp. (Porifera) and Poraniomorpha sp. (Asteroidea).

Environmental variables

The environmental information used for the analysis of fauna patterns versus environmental heterogeneity is listed in Table S1. For the broad scale analyses of biodiversity and communities, depth and frequency of 
Fig. 6 Fine scale analysis "Tromsøflaket". DCA plot of video sequences based on species composition in 252 video sequences from 48 video transects along the seabed. The arrows indicate the relationship between the environmental variables and the ordination axes. The length of the arrows represents the strength of the correlations. BPI bathymetric position index (one of the terrain indices)

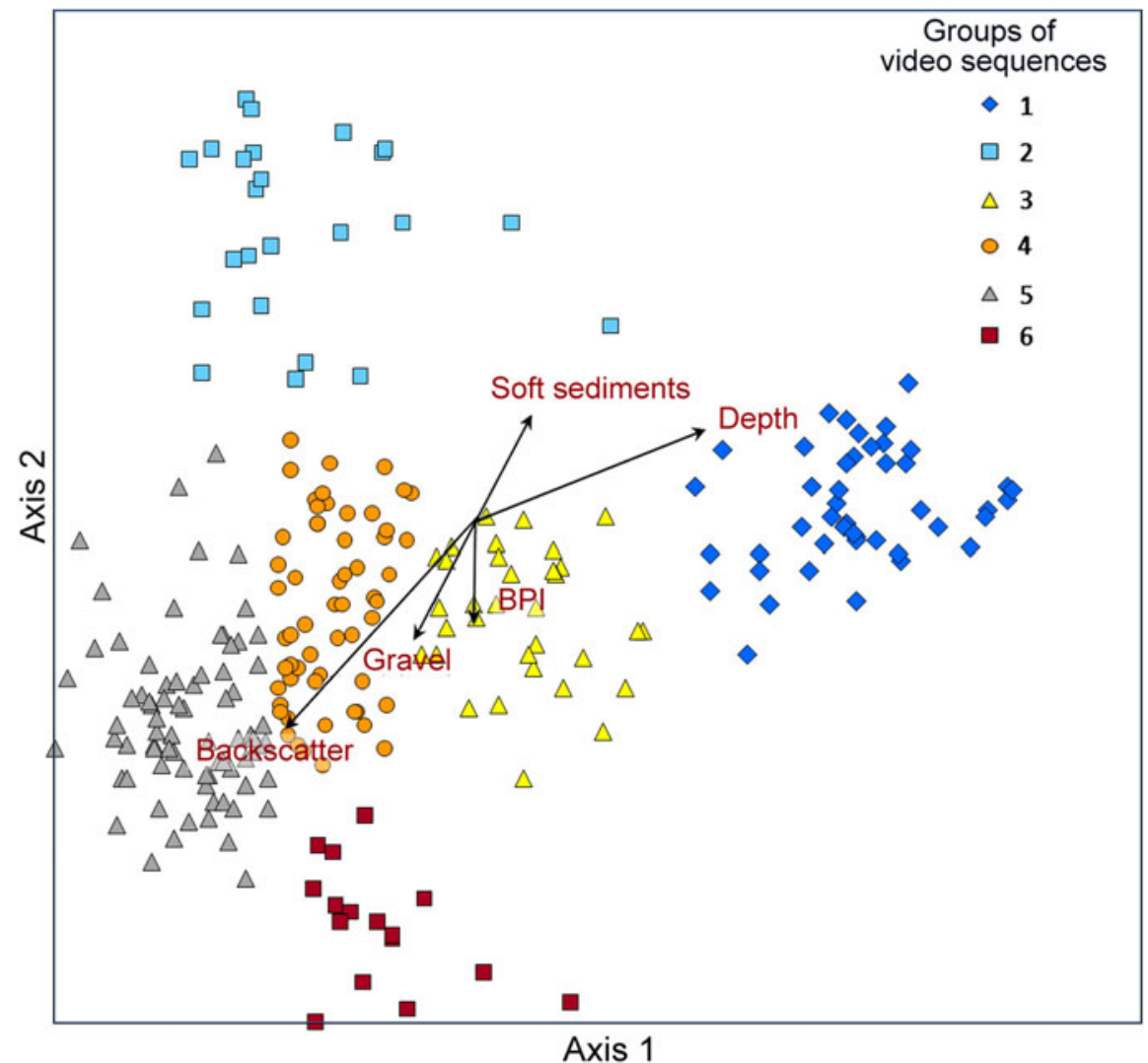

Axis 1 occurrence of nine bottom types were used as descriptors. For the fine scale analysis of the "Tromsøflaket" area depth and five terrain parameters (backscatter, slope, aspect, and fine and broad-scale BPI (BPI 50 and BPI 200) and curvature (see, Wilson et al., 2007; Dolan et al., 2009) were derived from multibeam data. Rather than simply using the values of each derived terrain parameter directly, the mean and standard deviation of each terrain variable was computed over $200 \mathrm{~m}$, the distance corresponding with the distance over which the video data were pooled. The percentage cover of six classes of bottom substrates (soft sediments [mud and sand], pebbles, cobbles, boulders and outcrops) was estimated to a precision of $5 \%$ intervals $(0,5,10, \ldots$, $100 \%$ ) from the $30 \mathrm{~s}$ video sequences, following the size classes as defined by the Wentworth scale (Wentworth, 1922), and calculated as mean for the same $200 \mathrm{~m}$ sequences as used for quantification of taxa. Occurrence of lebensspuren, burrows, and bottom trawl marks were counted and their densities were calculated for the same $200 \mathrm{~m}$ sequences as used for the rest of the video data.

\section{Sampling of macrofauna}

To document infauna, epifauna and hyperbenthos within the habitats, grab, beam trawl and RPepibenthic sled were used at about $25 \%$ of all stations documented with video. Mega- and macrofauna were documented to lowest possible taxonomic level and abundance and biomass were registered to be able to calculate production. It was not possible to use all samplers on all the locations due to sediment properties (e.g. high number of boulders) resulting in an uneven number of samples per station (Table S2).

Sampling of infauna was mainly conducted with a large van Veen grab $\left(0.25 \mathrm{~m}^{2}\right)$ with exception for station 7 and 9 where a $0.1 \mathrm{~m}^{2}$ van Veen grab was used and at station 68 where a small box corer $\left(0.1 \mathrm{~m}^{2}\right)$ was used. Samples were gently sieved over a $1 \mathrm{~mm}$ mesh and fixed in $5 \%$ buffered formalin until sorting and identification in the laboratory. Infauna abundances are given in $N \mathrm{~m}^{-2}$. Table $\mathrm{S} 2$ provides information about sampled fauna from the different stations. 
Epifauna was sampled by beam trawl (mesh size $2 \mathrm{~mm}, 2 \mathrm{~m}$ opening width, 5 min hauls, see Bergman et al., 2009 for gear description) and hyperfauna was sampled with a RP sled (mesh size $0.5 \mathrm{~mm}, 1 \mathrm{~m}$ opening width, $10 \mathrm{~min}$ hauls, see, Rothlisberg \& Pearcy, 1977; Buhl-Jensen, 1986 for a description).

The composition of macrofauna in the six biotopes that have been identified through the analysis of video registered megafauna, is compared with respect to diversity, biomass, productivity and functional groups.

Analyses of macrofauna diversity

The diversity in the six biotopes was compared for the different fauna components using the actual number of species sampled 'species richness $S$ ' and the expected number of species $\operatorname{ES}(n)$, in a given sample size estimated by rarefaction analysis (RA) (Hurlbert, 1971; Simberloff, 1978). RA makes it possible to compare species richness for a standardised sample size and is recommended when samples differ appreciably in number of individuals (Soetaert \& Heip, 1990; Magurran, 2004). The diversity index $H^{\prime}$ (Shannon \& Weaver, 1949) and evenness $J$ (Pielou, 1966) was calculated for each sample. Spearman rank correlation was used to study the relation between fauna abundance and diversity, and habitat heterogeneity in the identified biotopes.

Biomass and production data

For production calculation, all data were standardised to $1 \mathrm{~m}^{-2}$. Species wet biomass $\left(B, \mathrm{mg} \mathrm{m}^{-2}\right)$ and average body mass $(M, \mathrm{mg})$ were converted to joule $(\mathrm{kJ})$ by conversion factors taken from Brey (2005). Mean annual production $\left(P, \mathrm{~kJ} \mathrm{~m}^{-2} \mathrm{y}^{-1}\right)$ was estimated from species abundance $\left(N \mathrm{~m}^{-2}\right)$, biomass $\left(\mathrm{kJ} \mathrm{m}^{-2}\right)$, body mass $(\mathrm{kJ})$, depth $(\mathrm{m})$ and temperature $\left({ }^{\circ} \mathrm{C}\right)$ using the empirical multiple regression model of Brey (2001). Average biomass and production ( \pm standard deviation, SD) was calculated for the six biotopes on Tromsøflaket.

In order to identify whether community diversity affects biomass and production, correlation between species number $(S)$, Shannon's diversity $H_{(\log 2)}^{\prime}$, Pielou's evenness $(J)$ and biomass, production were analysed. An outlier analysis (Mahalanobis Distances, Barnett \& Lewis, 1994) was performed and 2 grab samples $(14,16)$ were excluded from the correlation analysis. Significance level was set to $<0.01$ and linear dependence (measure of correlation) is expressed as Pearson's $r$.

\section{Feeding modes}

Feeding modes were assigned to those species found to be dominant (i.e. comprising $90 \%$ of $B$ and $N$, respectively) in samples. Feeding mode information was extracted from Enequist (1949), Naylor (1972), Fauchald \& Jumars (1979), Lincoln (1979), Holte (1998), Berge \& Vader (2001), Holte (2004), Holte et al. (2004), Buhl-Jensen (1986) and Buhl-Mortensen (1996), as well as the databases of ERMS (European Register of Marine Species, www.marbef.org) and WoRMS (World Register of Marine Species, www.marinespecies.org). Species which could not be assigned to feeding modes were pooled in the group "unknown" (Cressa minuta, Idunella aequicornis, Liljeborgia fissicornis, L. pallida, Dendrotion spinosum, Tole laciniata, Flabellum macandrewi, Fungiacyathus fragilis, Cephalodiscus spp., Lyonsiella abyssicola). Feeding modes were not defined for higher taxonomic levels (e.g. Bivalvia, Amphipoda, Decapoda, Polychaeta and Gastropoda). Proportions of feeding mode $(\%)$ of total abundance, biomass and production in the six biotopes were analysed.

\section{Results}

Environmental description

\section{Broad scale}

The general composition of bottom types is described based on a broad-scale analysis of the 164 video transects surveyed in 2008. Bedrock was observed only in the fjord/coast landscape off Andfjorden and in a few patches on the Nordland/Troms area of the continental shelf. Gravel and boulders were most common on the banks. Below the upper slope the bottom type composition changed clearly, with increasing frequency of mud and sandy mud, whilst sand was absent.

Sandy gravel and gravelly sand was the most frequent bottom types present on 49 and $63 \%$ of the video transects, respectively (Table 2). They occurred 


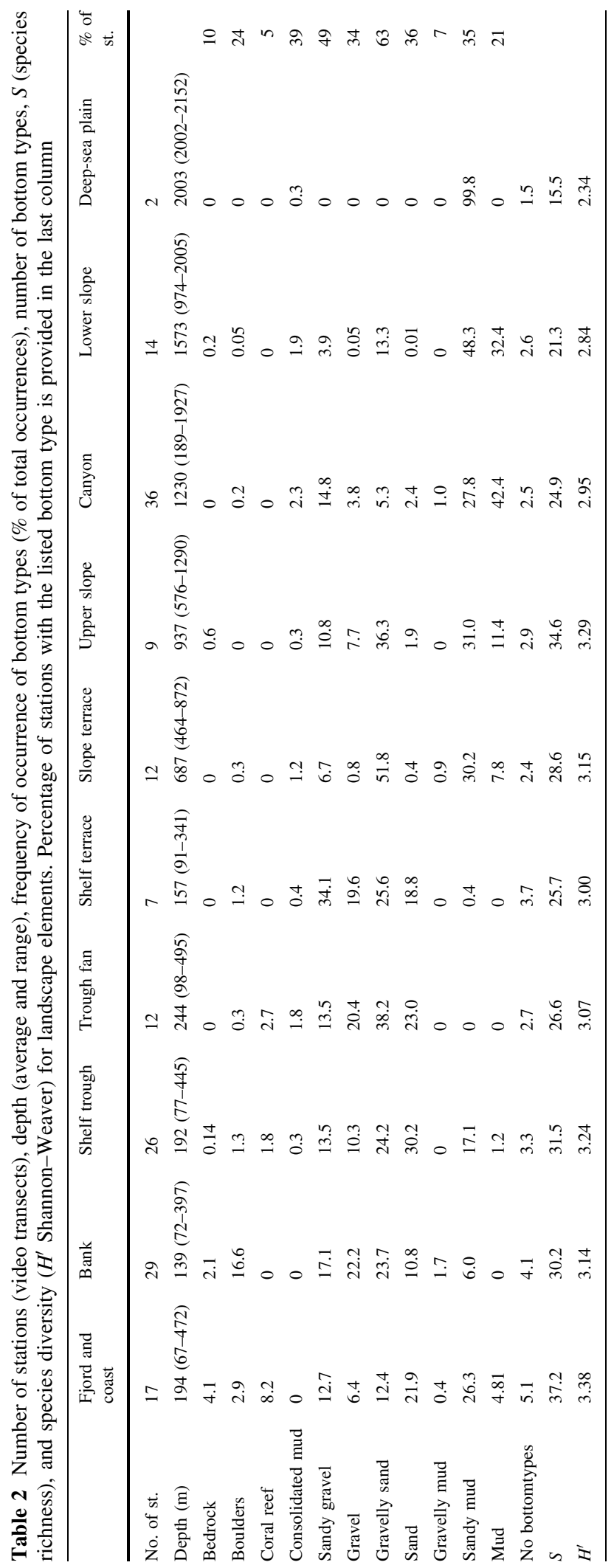


as large patches and covered on average about $40-50 \%$ of the seabed at transects where they occurred. Mud without gravel was less common ( $21 \%$ of all transects) but when it occurred it often covered more than $90 \%$ of the seabed along the video transects. Mud was most common in canyons and at the lower slope where it occurred along 42.4 and $32.4 \%$ of the video transects, respectively (Table 2). Consolidated sediment was observed along many of the deeper $(>1,000 \mathrm{~m})$ locations, but mostly as relatively small isolated patches. Boulder was most common on the banks where it occurred on $16.6 \%$ of the video transects, as part of the moraines that dominated large parts of the shallow shelf.

The number of bottom types observed along each video transect decreased with depth $(r=-0.44$, $P<0.005)$ whilst mud became more common $(r=0.55)$.

CTD casts performed during the 2008 cruises fitted well with the vertical zonation of water masses described by Hansen \& Østerhus (2000) and studies cited therein. A strong thermocline was observed between 600 and $900 \mathrm{~m}$ (Fig. 3). That represents the transition between a upper Atlantic and lower Arctic water mass. Table $\mathrm{S} 3$ provides results from correlation analysis of environmental descriptors used for the broad-scale analysis.

\section{Fine scale}

The seabed heterogeneity at fine scale is indicated by sediment composition from analysis of grab samples, video documentation of coverage of sediment classes and Multibeam backscatter and terrain analysis (environmental information is listed in Table S1).

There is a general increase in sediment heterogeneity from biotopes 1-6 shown by increased sediment coarseness, number of bottom types within video transects and rugosity. Mutibeam backscatter $(5 \times 5 \mathrm{~m}$ grid resolution) within biotopes $1-6$ indicates increased hardness of substratum. Rugosity was highest in biotopes 4 and 5. Video information revealed a gradient from a mean value of $99.9 \%$ soft sediment with $0.1 \%$ stones in biotope 1 to a mean of $78.5 \%$ soft sediment with a total of $21.4 \%$ stones in biotope 6 . Number of bottom types was highest in biotopes 4 and 5 . Information on sediment grain size composition based on sampled sediment was available only for biotopes 1-4. Grain size increased from biotopes 1-4, clay and silt decreased from 32 to $12 \%$ and 60 to $33 \%$, respectively, as sand and gravel increased from 7 to $50 \%$ and 0.8 to $3 \%$, respectively. In parallel, the amount of organic matter decreased from 6 to $4 \%$.

Megafauna composition at a broad scale compared with landscape elements

Large changes in composition of landscapes, bottom types, biodiversity and taxonomic composition occurred along the gradient from fjord/coast to the deep-sea plain. A total of 195 taxa (identified species, and unidentified taxa at levels between genera and classes) were recorded. The highest number of taxa was found at depths between 200 and $700 \mathrm{~m}$ (Fig. 7) with 37 to 43 taxa at locations in fjord/coast and trough fan landscapes (Fig. 8). Below this depth, the number of taxa per video transect decreased to between 7 and 20 taxa. Both the number of taxa and diversity $\left(H^{\prime}\right)$ were strongly correlated with number of bottom types recorded per video transect $(r=0.50$ and 0.47 , respectively, $P<0.005$ ) (Table 3; Fig. 9).

Six groups of video transects were identified by using DCA based on species composition in the 164 video transects from 2008 (Fig. 10). The video

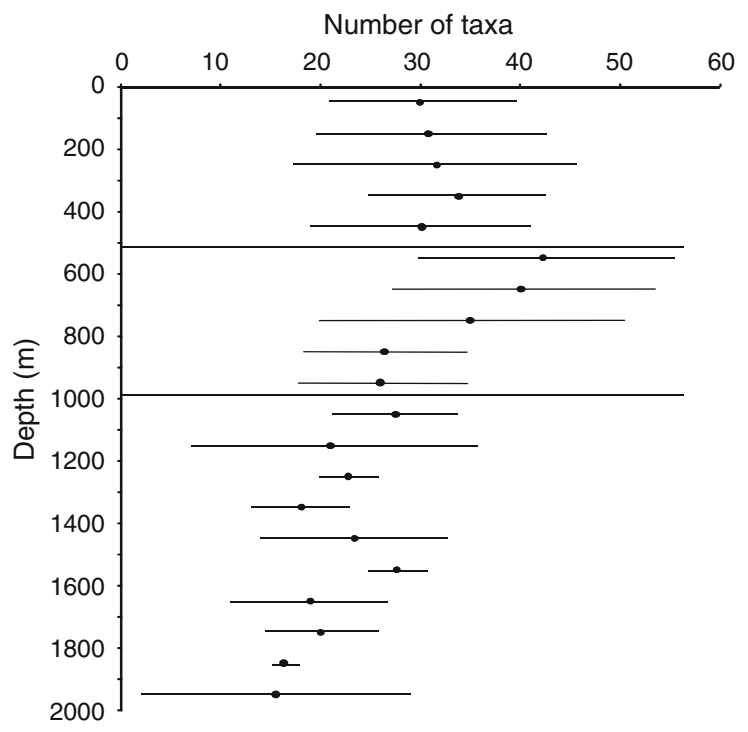

Fig. 7 The relationship between number of megafauna taxa observed during video transects and depth expressed as mean for 100-m depth intervals. Standard deviation and the transition zone between the upper Atlantic and lower Arctic water mass is indicated with horizontal lines 
Fig. 8 Idealized bottom profile from the coast off Nordland out to the deep-sea plain in the Norwegian Sea. The occurrence of landscapes and landscape profile together with composition of bottom types. Number of species observed during video recording is presented as mean for locations (standard deviations indicated by vertical lines). Dashed lines with different colours are used to show overlapping landscapes. The depth limits for different water masses are shown in zones above the profile. $N C W$ Norwegian Coastal Water, NAW North Atlantic Water, NSAIW

Norwegian Sea Arctic Norwegian Sea Deep Water elements is shown along the Intermediate Water, NSDW

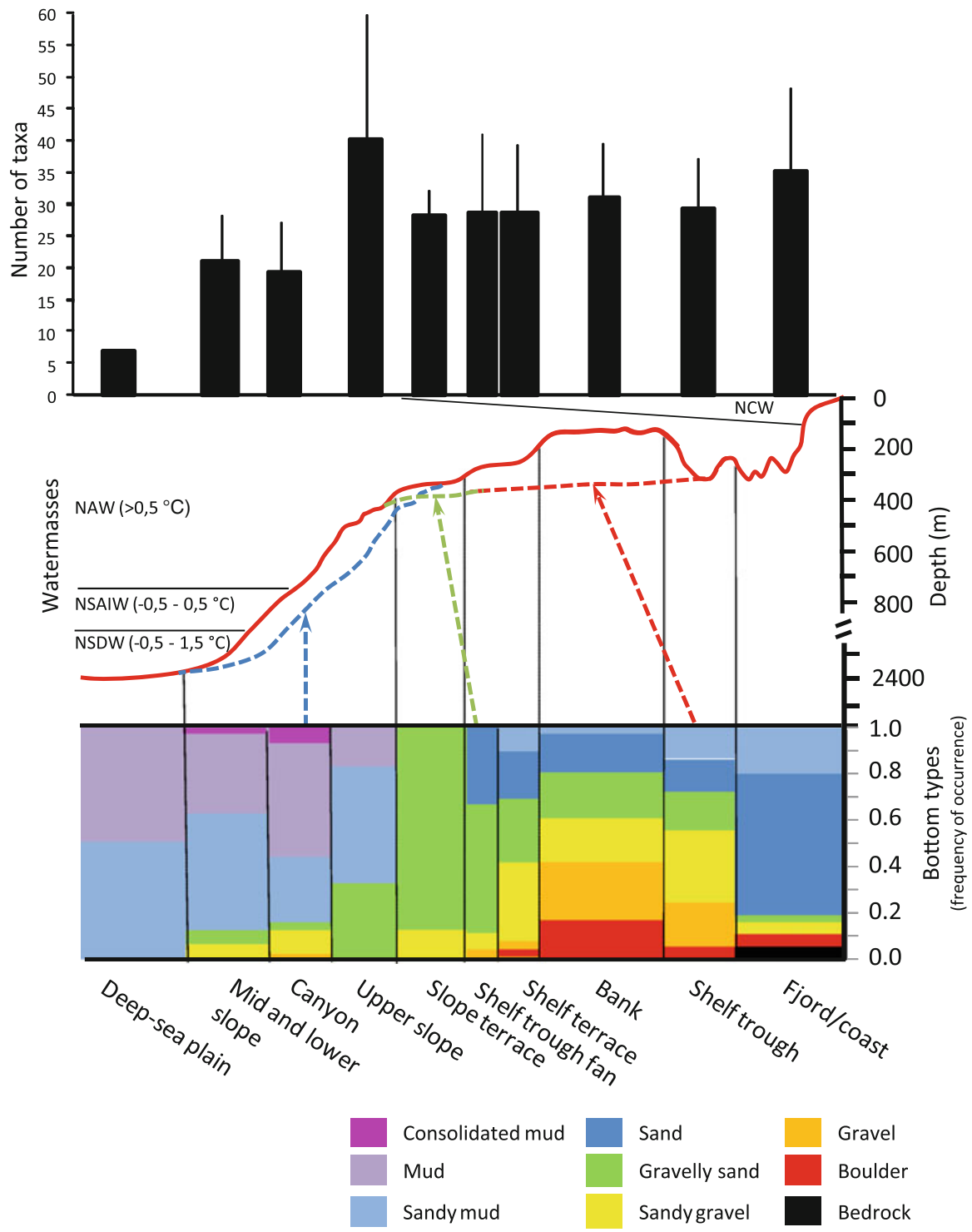

transects used for the broad-scale analyses reflect species composition accumulated over a distance of $700 \mathrm{~m}$, which we consider to be an adequate scale for investigating patterns at a landscape scale. The DCA results (Fig. 10) indicated that a combination of bottom types and landscapes from different depth zones was most important determining the taxonomic composition. The total variance ('inertia') in the species data was 4.368 .

Most of the variation was explained by depth (Pearson coefficient of determination with first axis: $\left.r^{2}=0.86\right)$ and frequency of occurrence of bottom with mud (Pearson coefficient of determination with first axis: $\left.r^{2}=0.34\right)$. However, these two factors were strongly correlated with each other $(r=0.55)$.

Based on the grouping of locations provided by the DCA analysis we classified the video transects into six broad-scale biotope groups indicating the following broad-scale biotopes: (1) coarse sediments on banks, (2) fine sediments in shelf trenches, (3) upper slope/ shallow canyon, (4) slope terrace, (5) fine sediments in deep canyon and (6) coarse sediments in deep canyon and lower slope.

Based on megafauna similarity, the predefined landscapes and landscape elements grouped together in relatively clear patterns (Fig. 10), but there were 
Table 3 Relation between diversity of megafauna and sediment descriptors used in the broad-scale analyses

\begin{tabular}{lrrr}
\hline & \multicolumn{1}{c}{$S$} & \multicolumn{1}{l}{$H^{\prime}$} & \multicolumn{1}{l}{$J$} \\
\hline Depth & $-\mathbf{0 . 3 9}$ & $\mathbf{- 0 . 4 2}$ & $\mathbf{- 0 . 2 2}$ \\
Bedrock & $\mathbf{0 . 1 8}$ & 0.15 & 0.05 \\
Boulders & 0.14 & 0.15 & 0.04 \\
Consolidated mud & -0.06 & -0.07 & -0.01 \\
Coral reef & $\mathbf{0 . 3 4}$ & $\mathbf{0 . 2 8}$ & 0.14 \\
Gravel & $\mathbf{0 . 2 7}$ & $\mathbf{0 . 2 4}$ & 0.03 \\
Gravelly mud & 0.11 & 0.10 & -0.04 \\
Gravelly sand & 0.04 & 0.02 & 0.01 \\
Mud & $\mathbf{- 0 . 3 2}$ & $\mathbf{- 0 . 3 2}$ & -0.06 \\
Sand & 0.01 & 0.06 & $\mathbf{0 . 2 2}$ \\
Sandy gravel & $\mathbf{0 . 2 3}$ & $\mathbf{0 . 2 2}$ & 0.06 \\
Sandy mud & $\mathbf{- 0 . 2 2}$ & $\mathbf{- 0 . 2 0}$ & $\mathbf{- 0 . 2 1}$ \\
No. of bottomtypes & $\mathbf{0 . 5 0}$ & $\mathbf{0 . 4 7}$ & 0.08 \\
Trawlmark & $\mathbf{0 . 1 8}$ & 0.18 & -0.09 \\
\hline S & &
\end{tabular}

$S$ number of species, $H^{\prime}$ Shannon's diversity index, $J$ evenness Values are linear correlation with significant values in bold $(N=165$, for $r>0.17, P<0.05)$

many examples of megafauna observations from the same landscape element occurring in several groups on the plot. The fauna of the lower slope and canyons was clearly different from the fauna in shallower areas on the shelf. One example was the glass sponges (Hexactinellida) which were both more common and more diverse at the deep locations. Video transects from deep locations in canyons and the lower slope formed a distinct group based on faunal composition. Two typical species here were the glass sponge Caulophacus arcticus and the seapen Umbellula encrinus. This group could further be divided in two with respect to sediment type, with one group for muddy locations and one representing locations with sandy mud. The three other groups separated transects from banks, fans in outer trough areas and upper slope/slope terraces (Fig. 10). Transects from shelf troughs were widely distributed along the second DCA axis and showed faunistic similarities with both trough fan and bank transects. The transects from the upper slope were more similar to bank transects than to lower slope and canyons.

Macrofauna composition at a fine scale at Tromsøflaket—comparing six biotopes

The abundance, wet weight and diversity of fauna are listed in Table S2. In the Tromsøflaket area, a total of 582 species were sampled, 366 infauna species, 171 hyperfauna (crustacean) species and 182 epifauna species.
Fig. 9 The relationship between number of megafauna taxa observed during video transects and number of bottom types. Standard deviation is indicated by vertical lines

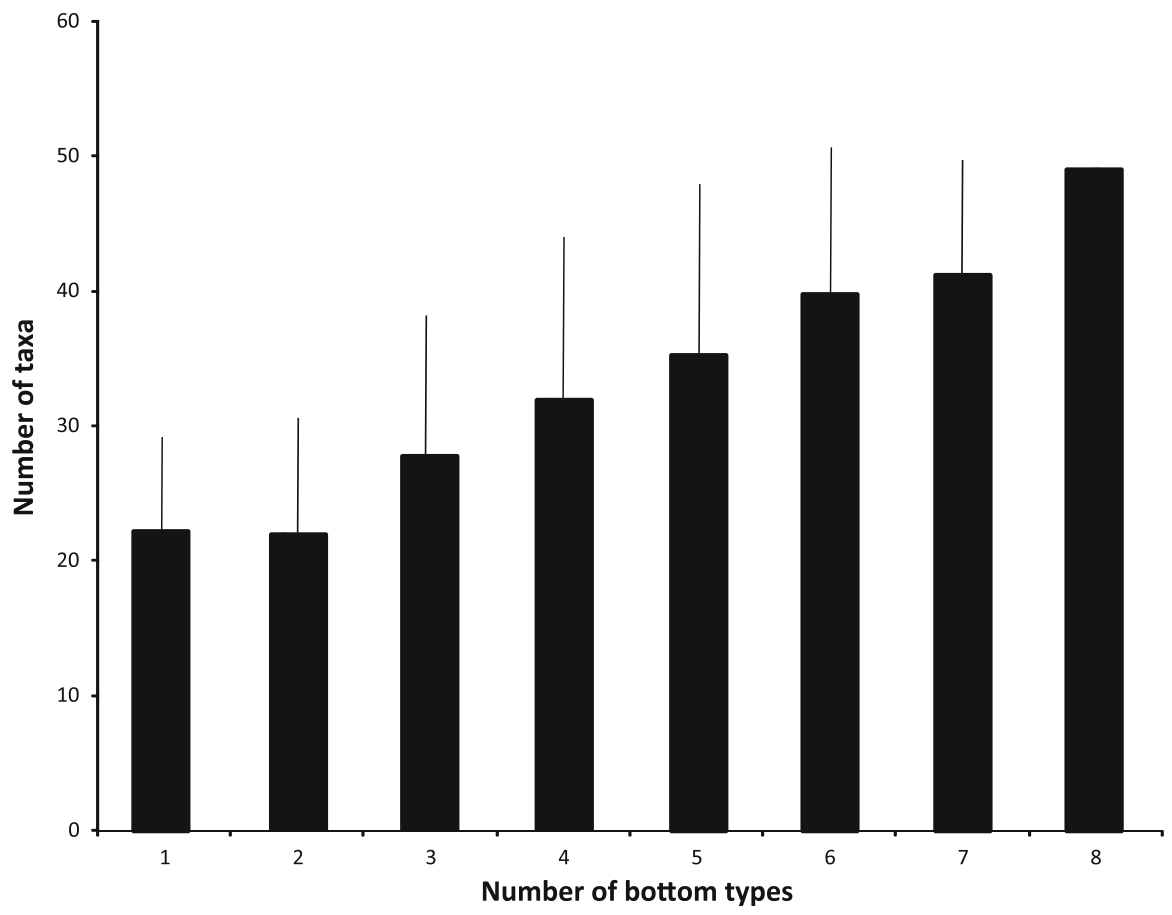




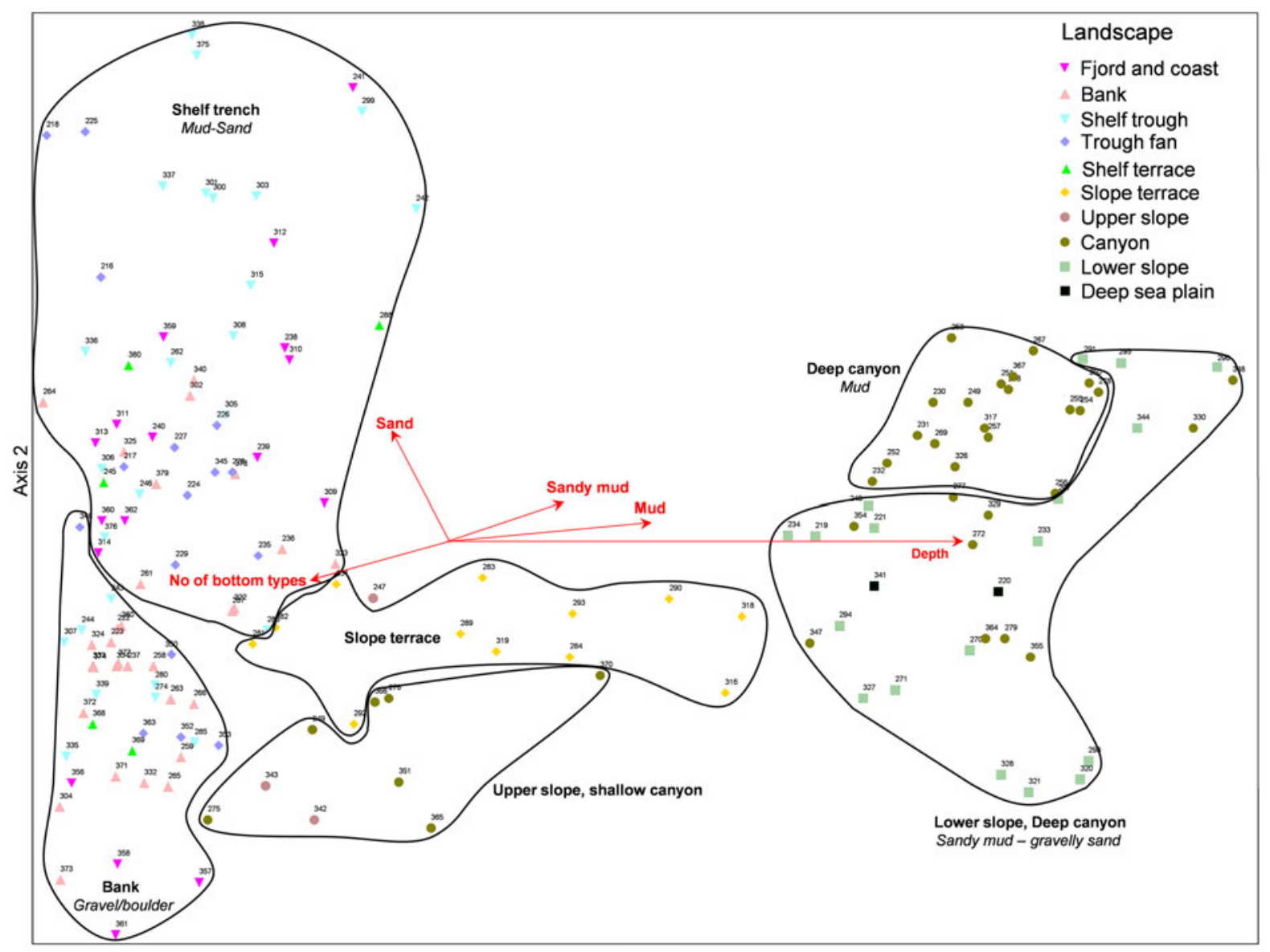

Axis 1

Fig. 10 Plot of video transects grouped by DCA based on species composition (presence/absence data) along 164 video transects along the seabed. The arrows indicate the relationship between the environmental variables and the ordination axes.

The infauna, hyperfauna and epifauna species that are numerically dominant in each biotope are listed in Table 4. Biotope 1 was typified by: the glass sponge $A$. pennatula (Hexactinellida), S. borealis (Demospongia), Ophiura sarsi (Ophiuroidea), Mendicula ferruginosa (Bivalvia) and Maldane sarsi (Polychaeta). In biotope 2, the sponge Aplysilla sulfurea and the squat lobster Munida sarsi were common megafauna. Nepthtys sp. together with O. sarsi, Amphilochus manudens and the bivalves Dacrydium vitreum and Limposis minuta were common. In biotope 3, $S$. borealis was present together with the echinoderms Cremaster granularis and $S$. tremulus. The bivalve Modiolula phaseolina and the brachiopod
The length of the arrows represents the strength of the correlations. Different symbols for video transects are used to indicate which landscape they occurred in. Six identified groups are outlined

Macandrevia cranium were also common. Biotope 4 was dominated by the brachiopod $M$. cranium which occurred together with the anemone Actinostola callos $a$ and the polychaet Pista cristata. Also in biotope 5, $M$. cranium was numerous. Together with the sponge $P$. ventilabrum, the sipunculid worm Onchnesoma squamatum and the brittle star Ophiopholis aculeata contributed numerically to the fauna. Biotope 6 had the coarsest substratum and only a few samples could be collected and thus of the fauna information is from video observations. Here, again $S$. borealis was common together with $M$. sarsi and S. tremulus. In addition, the ostracods Macrocypris angusta and M. minna were very common. 


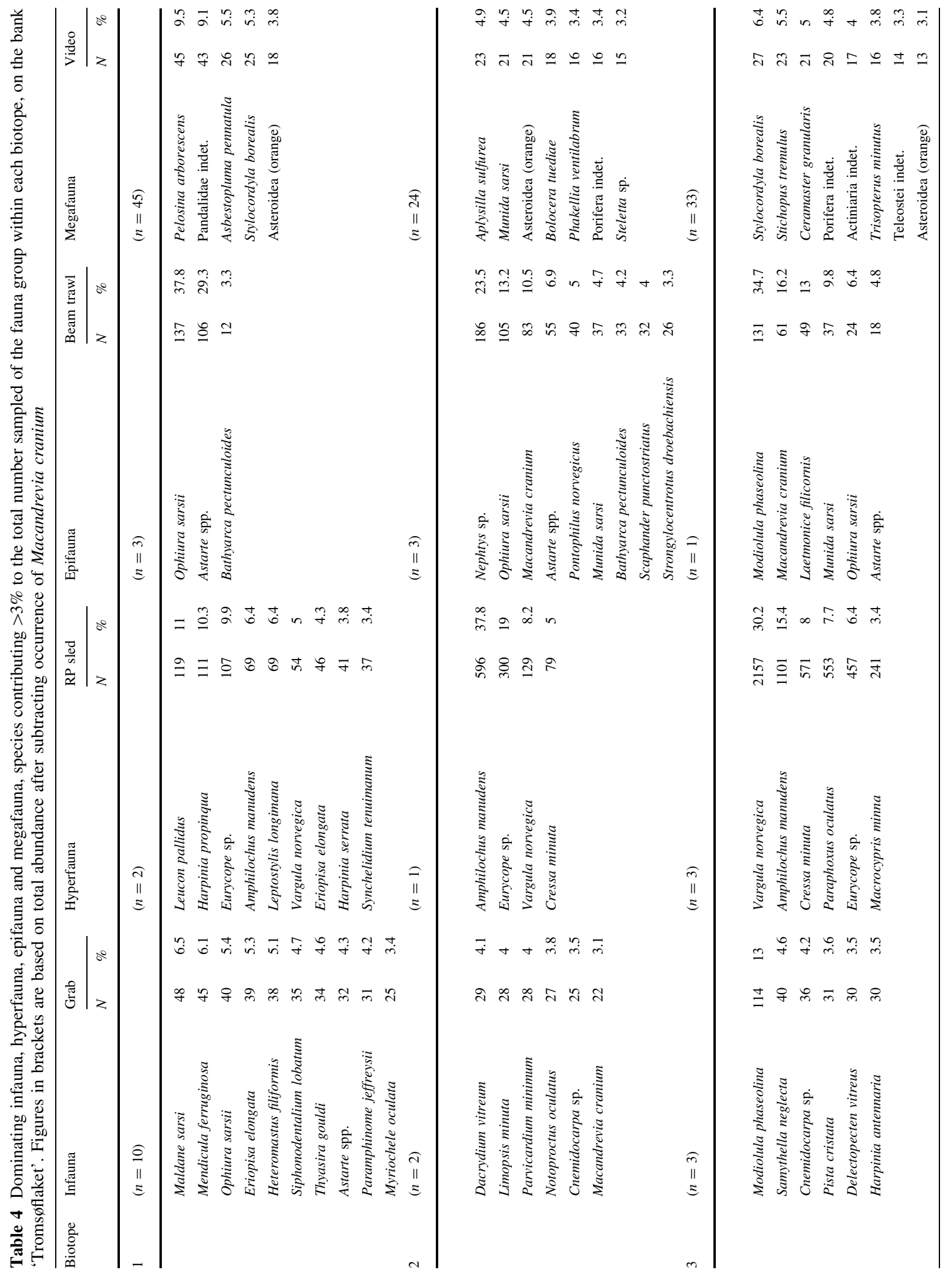




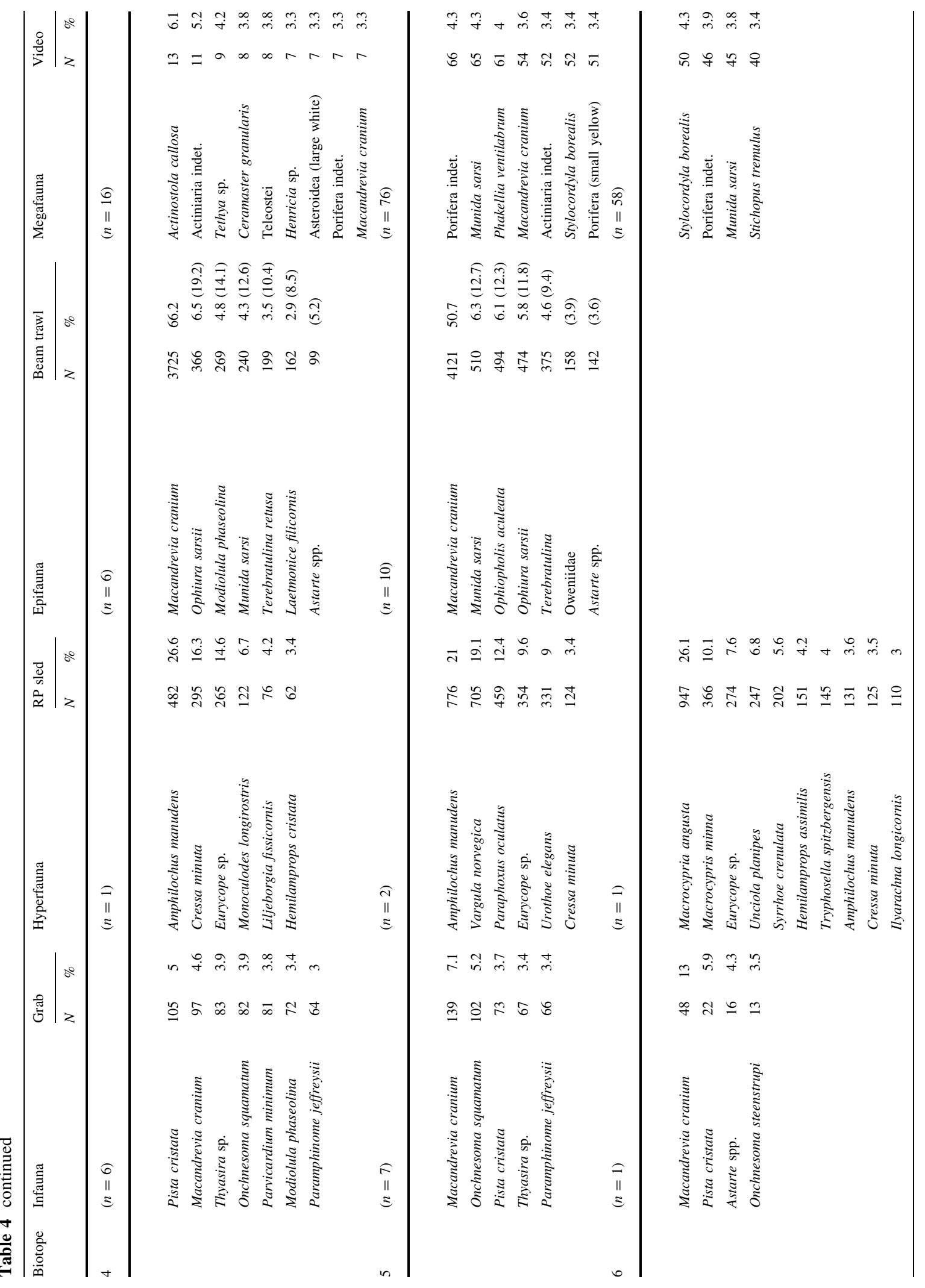




\section{Abundance and biomass}

The abundance of all fauna groups increased in general going form biotope 1 to 6 with the weakest trend for megafauna which was most abundant although, with large variability in biotope 2 (Fig. 11; Table S3). Because sampling of fauna in the stone dominated biotope 6 was difficult, the information came mainly from video. Biomass of epifauna was highest in biotopes 4 and 5, whereas infauna was also abundant in biotope 3 . Interestingly, infauna had a low biomass in the homogenous soft bottom biotopes 1 and 2 . The hyperfauna revealed no clear trend with regards to the different biotopes. Correlation between abundance and biomass and sediment descriptors is shown in Table S4. Megafauna abundance was strongest correlated with backscatter $(\mathrm{r}=-0.28, P<0.005)$. Epifauna abundance and biomass showed a strong and significant correlation with $\%$ gravel, $r=0.97$ as the only co-varying environmental factor. Abundance and biomass of hyperfauna was negatively correlated with slope and rugosity, and in addition abundance was negatively correlated with soft sediment. Infauna abundance showed highest correlation with depth $(r=-0.63)$ and backscatter $(r=0.55)$. Biomass of infauna was positively correlated with $\%$ cover of stones $(r=0.50)$ and negative with $\%$ cover of clay $(r=-0.74)$.

\section{Species diversity}

For epifaunal species, species number increased with hardness of the bottom and \% cover of boulders. There was a clear increase both in species richness $(S)$ and expected number of species (ES (120)) with \% cover of boulder $(r=0.60)$ and backscatter signal $(r=0.56)$. In contrast, diversity $\left(H^{\prime}\right)$ and evenness $(J)$ decreased with increased presence of gravel, $r=-0.86$ and -0.92 , respectively (Table S4).

For hyperfauna, expected number of species and diversity increased with depth $\left(H^{\prime}, r=0.72 ; J\right.$, $r=0.82$; ES (240), $r=0.66)$ and species richness $(S)$ increased with \% sand $(r=0.90)$ and was negatively correlated with rugosity and clay $(r=$ -0.66 and $r=-0.96$ ).

Interestingly infauna species richness and diversity increased significantly with backscatter signal, i.e. hardness of bottom ( $\mathrm{S}, r=0.67 ; H^{\prime}, r=0.54$; ES (100), $r=0.68)$ and with number of bottom types
( $S, r=0.63$; ES(100), $r=0.70)$. Whilst number of species (S and ES) was negatively correlated with depth and \% silt.

There was a clear increase in species number $(S)$ going form biotope 1 to 6 for all macrofauna groups (Fig. 12). Species richness increased from a mean per station of 23 to 54 for epifauna, from 47 to 72 for hyperfauna, and from 35 to 99 for infauna. For $H^{\prime}$ and evenness $(J)$, the trends are less clear. For epifauna, there was a trend of decreasing evenness with increased heterogeneity in biotopes 4 and 5. Hurlbert's ES did not reveal any trend for infauna except for a general increase with increased heterogeneity.

Rarefaction curves (Fig. 13a-d) show the expected number of species for megafauna, epifauna, hyperfauna and infauna in the six biotopes. For megafauna, the curves were not clearly different, however, the steepest curves belonged to biotopes 4-6 and the lowest with signs of levelling off were biotopes from 1 to 3 . For epifauna, the curves from biotopes 2 and 5 were steepest and highest indicating high diversity, whilst curves from biotopes 1,3 and 4 were below. The rarefaction curves for hyperfauna were not very well separated but had some similarities to the curves for epifauna. Biotope 5 had the highest curves together with biotope 2 which indicate higher diversity than for biotopes 1, 3 and 4. For infauna, the curves for biotopes 4 and 5 were clearly steeper and higher than for the other biotopes. Biotope 1 had the lowest and shortest curves, whilst biotopes 3 and 4 seemed to be at an intermediate level.

\section{Production and biomass}

\section{Biotope differences}

Production and biomass of infauna sampled by grab (Fig. 14a) was highest in biotope $3(35 \pm 17 \mathrm{~kJ}$ $\mathrm{m}^{-2}$ year $^{-1}, 22 \pm 17 \mathrm{~g} \mathrm{~m}^{-2}$ ), due to the bivalve $M$. phaseolina, and lowest in biotope $1\left(8 \pm 4 \mathrm{~kJ} \mathrm{~m}^{-2}\right.$ year ${ }^{-1}, 5 \pm 3 \mathrm{~g} \mathrm{~m}^{-2}$ ). This bivalve is not strictly infaunal (it lives on the sediment). Production and biomass of epifauna (Fig. 14b) was highest in biotope 4 with $5 \pm 8 \mathrm{~kJ} \mathrm{~m}^{-2}$ year $^{-1}$ and $10 \pm 18 \mathrm{~g} \mathrm{~m}^{-2}$, respectively, caused by the high occurrence of M. cranium (Brachiopoda). Production was lowest in biotope $1\left(0.6 \pm 0.3 \mathrm{~kJ} \mathrm{~m}^{-2}\right.$ year $\left.^{-1}\right)$ and in biotope 2 for epifaunal biomass $\left(0.7 \pm 0.7 \mathrm{~g} \mathrm{~m}^{-2}\right)$. The Macrocypria angusta, M. minna (Ostracoda) and 

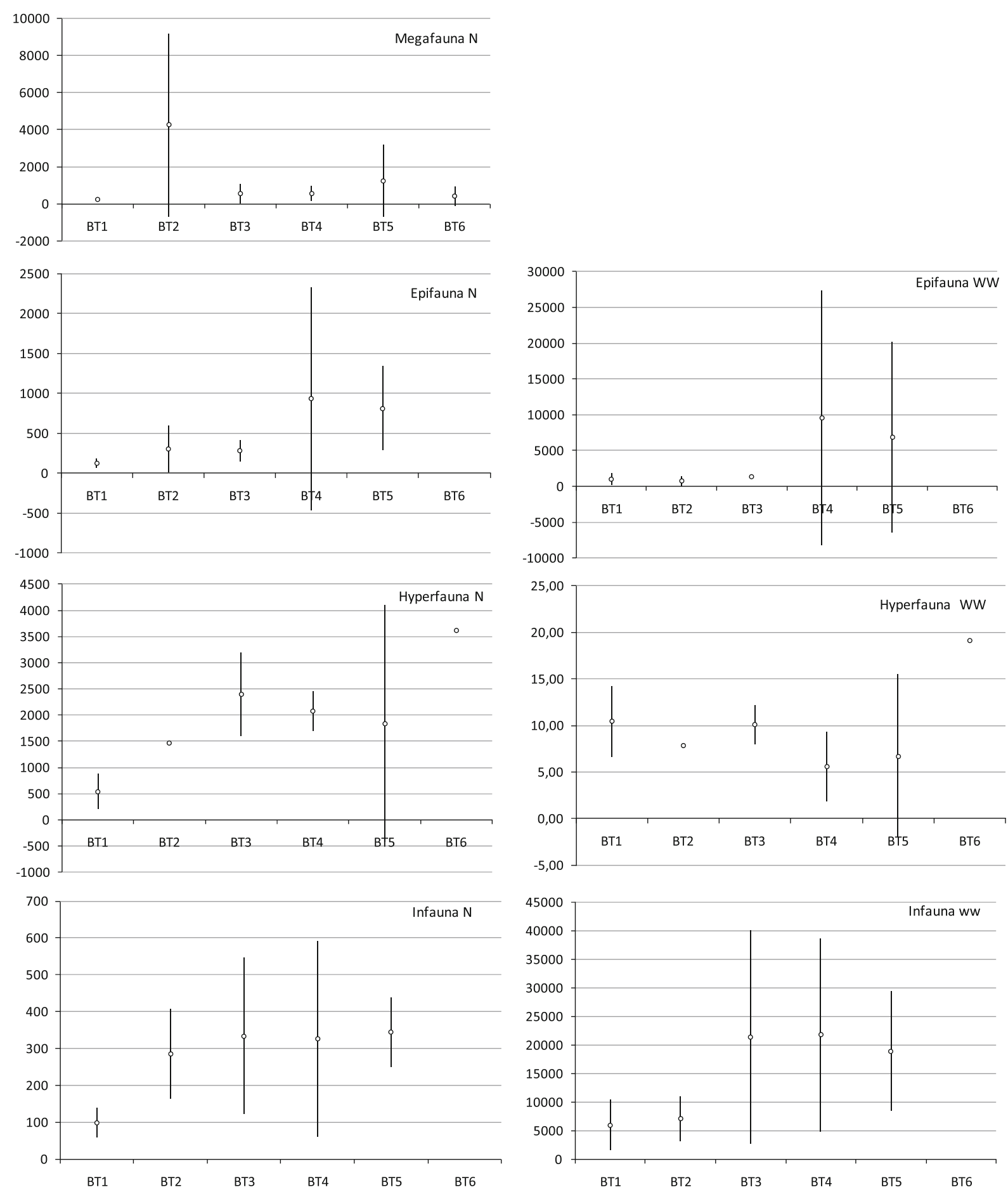

Fig. 11 Mean and standard deviation for the number $(\mathrm{N})$ of individuals and wet weight $\left(\mathrm{mg} \mathrm{m}^{-2}\right)$ sampled in the six biotopes (BT1BT6) in the area "Tromsøflaket"

Epimeria loricata (Amphipoda) were responsible for the highest production and biomass (Fig. 14c) of hyperfauna in biotope $6\left(0.12 \mathrm{~kJ} \mathrm{~m}^{-2}\right.$ year $^{-1}$, $\left.0.02 \mathrm{~g} \mathrm{~m}^{-2}\right)$. Production $\left(0.6 \pm 0.3 \mathrm{~kJ} \mathrm{~m}^{-2}\right.$ year $\left.^{-1}\right)$ and biomass $\left(0.7 \pm 0.7 \mathrm{~g} \mathrm{~m}^{-2}\right)$ were lowest in biotopes 1 and 2, respectively. 

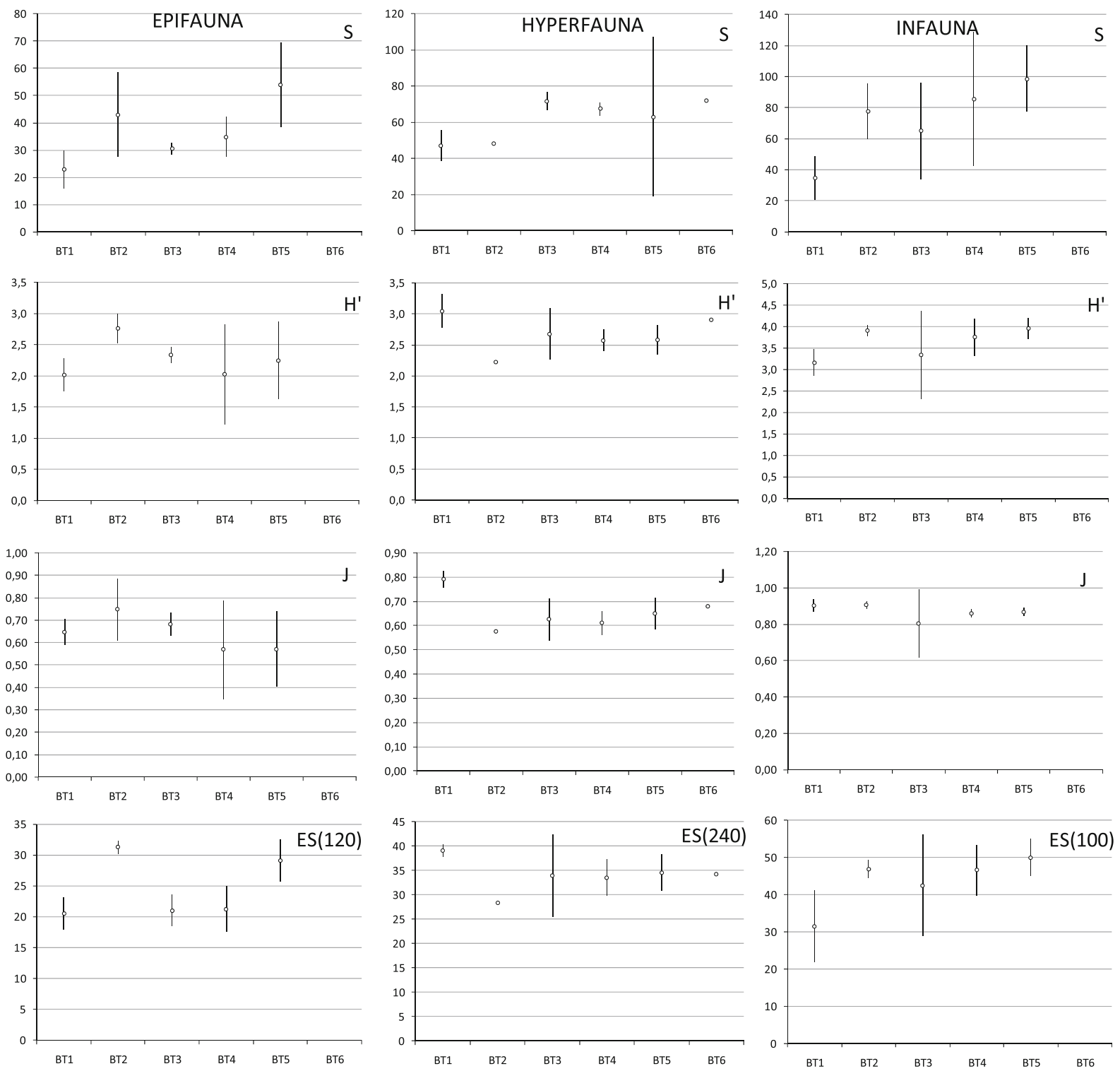

Fig. 12 Mean and standard deviation for diversity in the six biotopes (BT1-BT6) in the area "Tromsøflaket". $S$ number of species, $H^{\prime}$ Shannons index, $J$ Pielous evenness index, $\mathrm{ES}(n)$ expected number of species (sample size)

\section{Relation between biodiversity and biomass and production}

Infaunal production $(P)$ and biomass $(B)$ increased significantly $(P<0.05)$ with higher number of species (S) (Fig. 15a; $r$ of $P=0.65, B=0.50$ ) and higher values of $H^{\prime}$ (Fig. $15 \mathrm{~b} ; r$ of $P=0.66, B=0.50$ ). For epifauna $P$ and $B$ decreased significantly $(P<0.05)$ with increased diversity, $r=-0.68\left(H^{\prime}\right)$ and $r=$ $-0.71(J)$, and $r=-0.69\left(H^{\prime}\right)$ and $r=-0.69$
$(J)$ respectively (Fig. 15e, f). Production and biomass of hyperfauna revealed no clear trends related to number of species, $H^{\prime}$ and $J$ (Fig. $15 \mathrm{~g}-\mathrm{i}$ ).

Feeding-mode proportions

The proportion of organisms with different feeding mode is shown in Fig. 16. There seems to be an overall trend that biotopes 1 and 2 differed from biotopes 4-6, whilst biotope 3 was between these 2 groups. Biotopes 

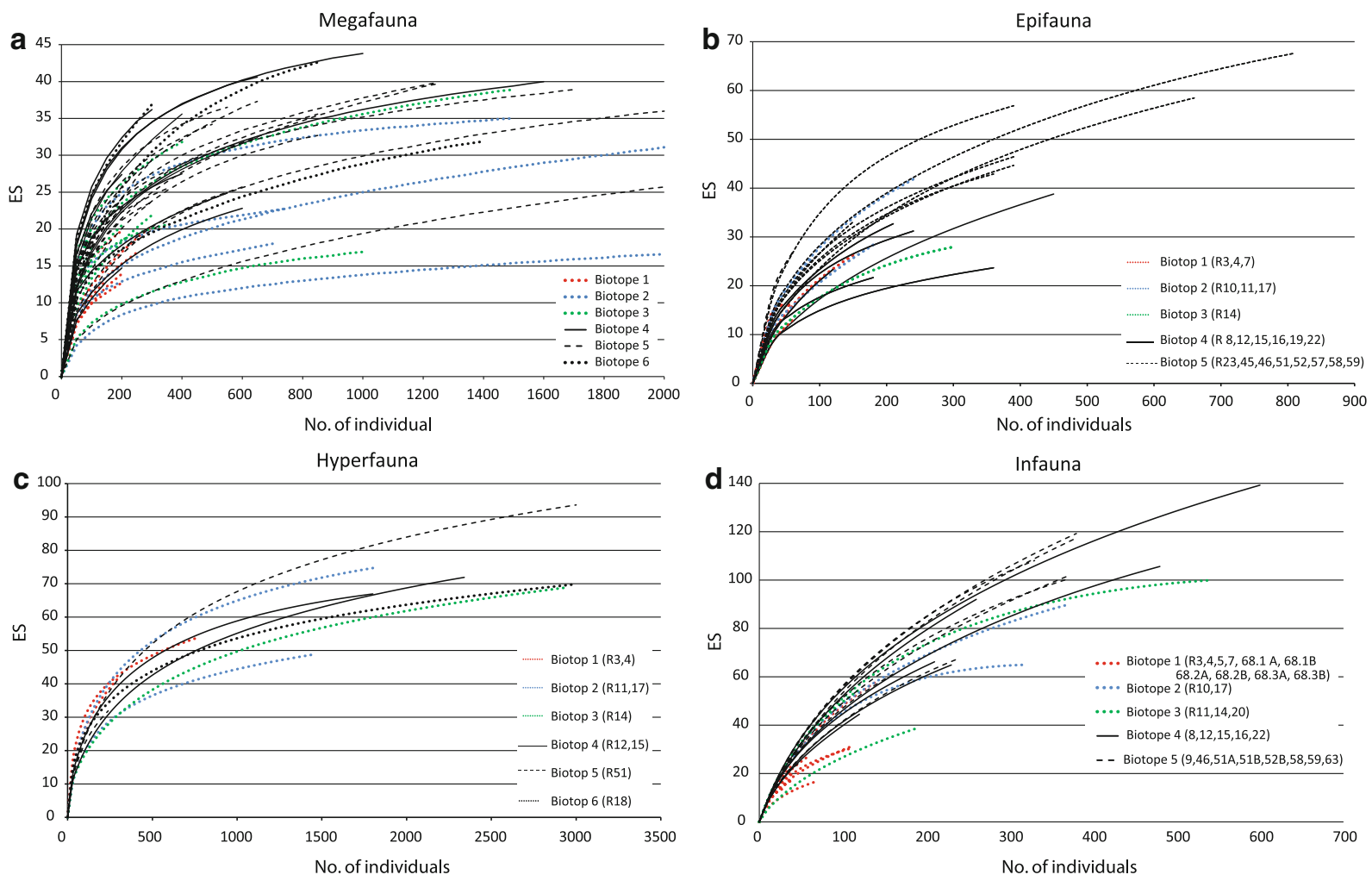

Fig. 13 Rarefaction curves for: a megafauna based on 56 video records representing 6 biotopes, $\mathbf{b}$ epifauna based on 21 beam trawl samples from five biotopes, $\mathbf{c}$ hyperfauna based on $9 \mathrm{RP}$ -

sled samples from six biotopes and $\mathbf{d}$ infauna based on 29 grab samples from five biotopes

1 and 2 were dominated by predator/scavenger, contributing to infaunal production with 42 and $45 \%$, respectively, to epifaunal abundance with 51 and $69 \%$ and to production with 70 and $79 \%$. Contribution to hyperfauna biomass was 48 and $68 \%$ and to production 42 and $45 \%$ respectively. Most dominant predating/scavenging species were Paramphinone jeffreysii, O. sarsii, Nephtys spp., Crangon allmanni and Munida spp. For hyperfauna, the burrowing subsurface deposit feeders dominated the abundance contributing in BT 1 and BT 2 with 45 and $71 \%$ respectively, mainly attributed to the species Eurycope spp. and A. manudens (which are also characterised to feed as grazers and commensal, respectively). Suspension feeders represented the largest part of the infaunal biomass in BT 1 and BT 2 (41 and $64 \%$ respectively), dominated by the species Astarte spp. and Hornera lichenoides.

The infauna of biotope 3 was characterised by a high abundance (48\%), biomass (81\%) and production (65\%) of suspension feeders, whereas the epifaunal

community was dominated by predator/scavengers with $B=54 \%, N=36 \%$ and $P=41 \%$, and interface feeders, i.e. those species that are able to switch feeding mode between surface deposit feeding, interface grazing and facultative suspension feeding, in epifaunal biomass $(26 \%)$ and hyperfuna abundance $(51 \%)$, biomass $(49 \%)$ and production $(38 \%)$. The most dominant suspension feeding species were M. phaseolina and Astarte spp., predating/scavenging species $O$. sarsii and $M$. sarsi and the interface feeding species $S$. tremulus and Vargula norvegica.

Biotopes 4-6 was dominated by suspension feeders. In BT 5 and 4 contributing with 32 and $39 \%$ to the abundance, 73 and $87 \%$ to the biomass and, 45 and $60 \%$ to the production of infauna. The epifauna in BT 5 and 4 was also dominated by suspension feeders that contributed with, 90 and $93 \%$ to the abundance, 86 and $92 \%$ to the biomass, and 73 and $81 \%$ to the production of epifauna. The hyperfauna was, however, dominated by interface feeders that contributed $38-49 \%$ to the abundance (BT 4: 38\%, BT 5: 49\%, BT 6: 49\%), 
Fig. 14 Average production $\left(P, \mathrm{~kJ} \mathrm{~m}^{-2}\right.$ year $\left.^{-1}\right)$ and biomass $(B$, $\mathrm{mg} \mathrm{m}^{-2}$ ) of biotopes (1-6) for: a infauna [no. of samples: $1=10,2=2$, $3=3,5=5,5=9$ and $6=$ no data (n.d.)],

b epifauna [no. of samples:

$1=3,2=2,3=2,4=6$, $5=10$ and $6=$ no data(n.d.)], and $\mathbf{c}$ hyperfauna [no. of samples: $1=2$, $2=1,3=2,4=2,5=2$ and $6=1]$. Vertical lines indicate standard deviation

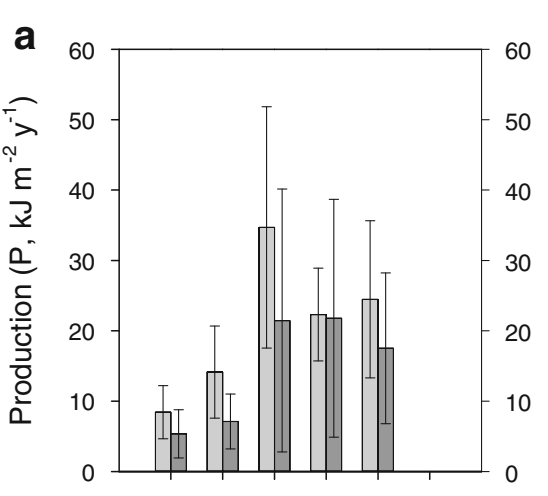

b
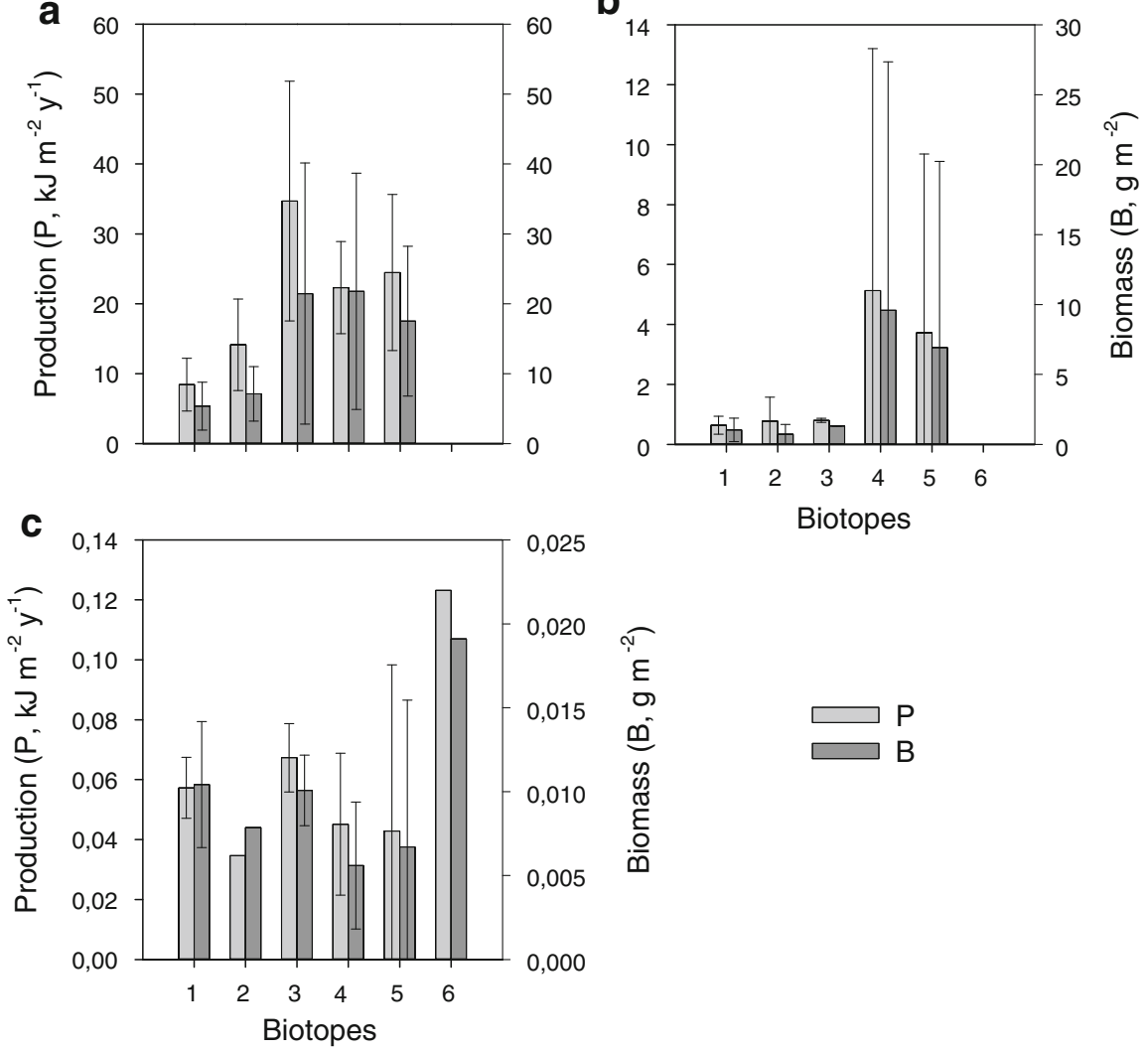

$22-39 \%$ to the biomass, and $24-27 \%$ to the production of hyperfauna. The dominant suspension feeders were M. cranium, M. phaseolina, H. lichenoides and Astarte spp. The interface feeders were dominated by Paraphoxus oculatus, $V$. norvegica and $M$. angusta. The subsurface deposit feeders were also an abundant part of the hyperfauna (BT 6: $25 \%$ to BT 5: $38 \%$ ), caused by $A$. manudens which are also known to feed commensally.

\section{Discussion}

This study documents broad and fine scale patterns of species composition and diversity in relation to habitat features (distribution of water masses, landscapes, landscape elements, terrain and composition of bottom types) at different scales. The measurement of habitat heterogeneity is not straight forward since it is highly scale dependent. This is illustrated by variable species diversity on similar bottom types in different landscape settings (Figs. 8, 10).
The number of taxa observed on video showed a decrease with depth with a maximum between 200 and $700 \mathrm{~m}$ (Fig. 7), representing the continental shelf break and the upper slope. Below this depth there was a gradual decrease down to around 1,300 $\mathrm{m}$. The area of the shelf break is important in this context with relatively coarse grained sediments, elevated current speed and enhanced plankton production (Babichenko et al., 1999). The temperature and salinity is relatively stable around the depths of maximum species richness.

Hardbottom substrates are a limiting resource for sessile invertebrates in deep water and also offer high degree of topographic relief, which is associated with variability of hydrodynamic conditions. Species diversity was positively correlated with habitat heterogeneity measured as the number of bottom types occurring along a video transect and as the percentage cover of hard bottom. The highest diversity was found on bottoms with mixed bottom substrates with a grain size less than boulders $(<25 \mathrm{~cm})$ indicating that the fine scale heterogeneity is highly important for the biodiversity. Along these lines Williams et al. (2010) 

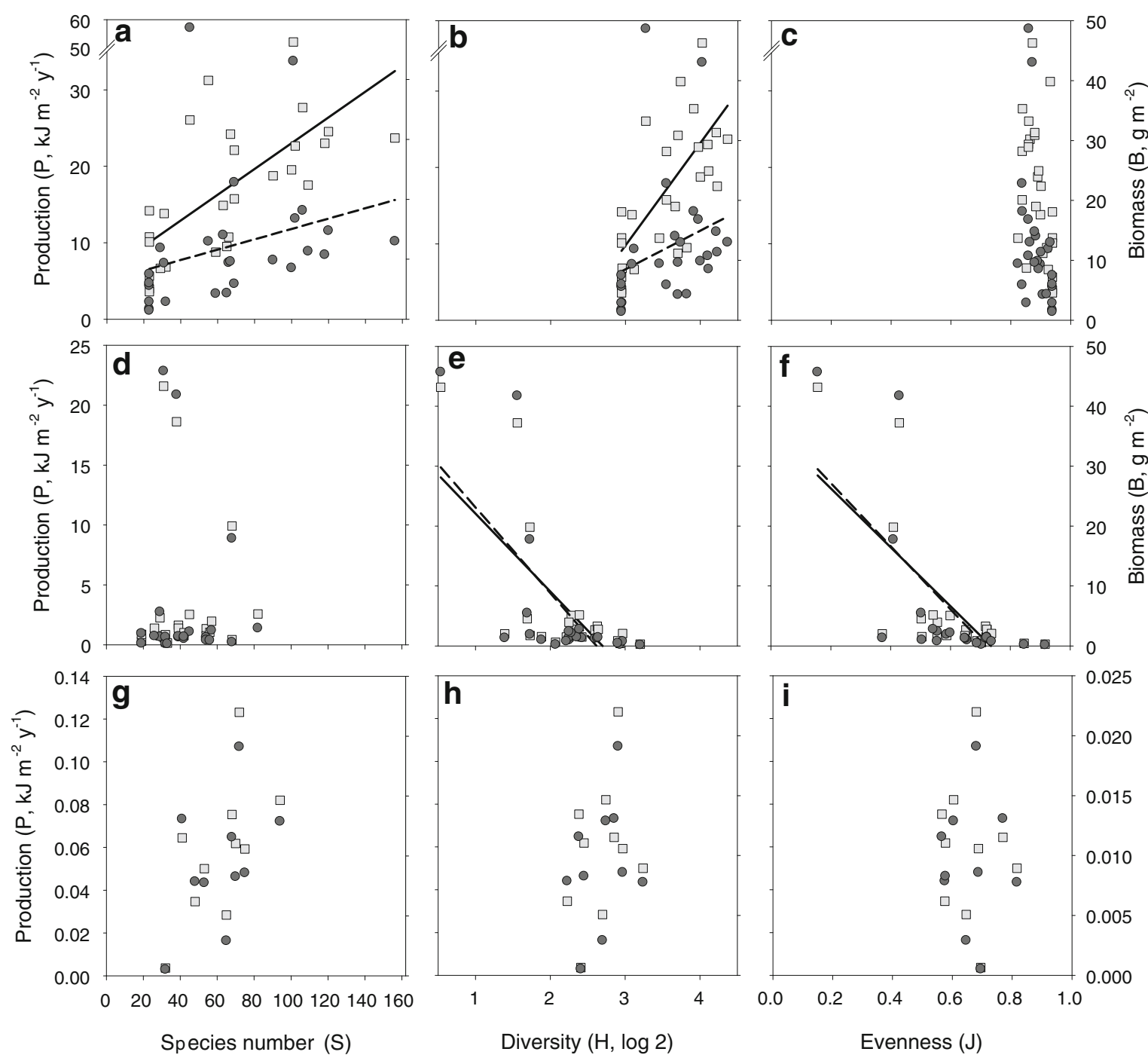

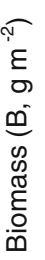

Fig. 15 Relation between production $\left(P, \mathrm{~kJ} \mathrm{~m}^{-2}\right.$ year $\left.{ }^{-1}\right)$, biomass $\left(B, \mathrm{~g} \mathrm{~m}^{-2}\right)$ and number of species $(S)$, Shannon's diversity $H_{(\log 2)}^{\prime}$, and Pilou's $(J)$, for infauna $(\mathbf{a}-\mathbf{c})$, epifauna $(\mathbf{d}-$

suggest, in a recent study of megabenthos on the Australian shelf, that hardbottom types represents critical elements of habitat heterogeneity nested within the larger scales of other influential covariates.

Our results indicate that broad-scale landscape elements and general hydrography are of importance for the distribution and composition of megafauna. However, in order to be able to define finer scale units of megafauna habitats (detailed substrate composition, current regime, etc.), more factors must be taken into f) and hyperfauna $(\mathbf{g}-\mathbf{i})$. Only significant correlations $(P<0.05)$ between $P$ (solid line), $B$ (dashed line) and $S, H^{\prime}$ and $J$ were included in the figures

account and the taxonomic data must be analysed more rigorously. For the characterization of habitats and biotopes at a lower classification level, more information about infauna and epifauna from bottom samples are required. This aspect is covered by analyses of macrofauna material collected as part of the MAREANO programme.

Depth was identified as the environmental factor explaining most of the faunistic variation in the material. It is worth remembering that depth per se is 

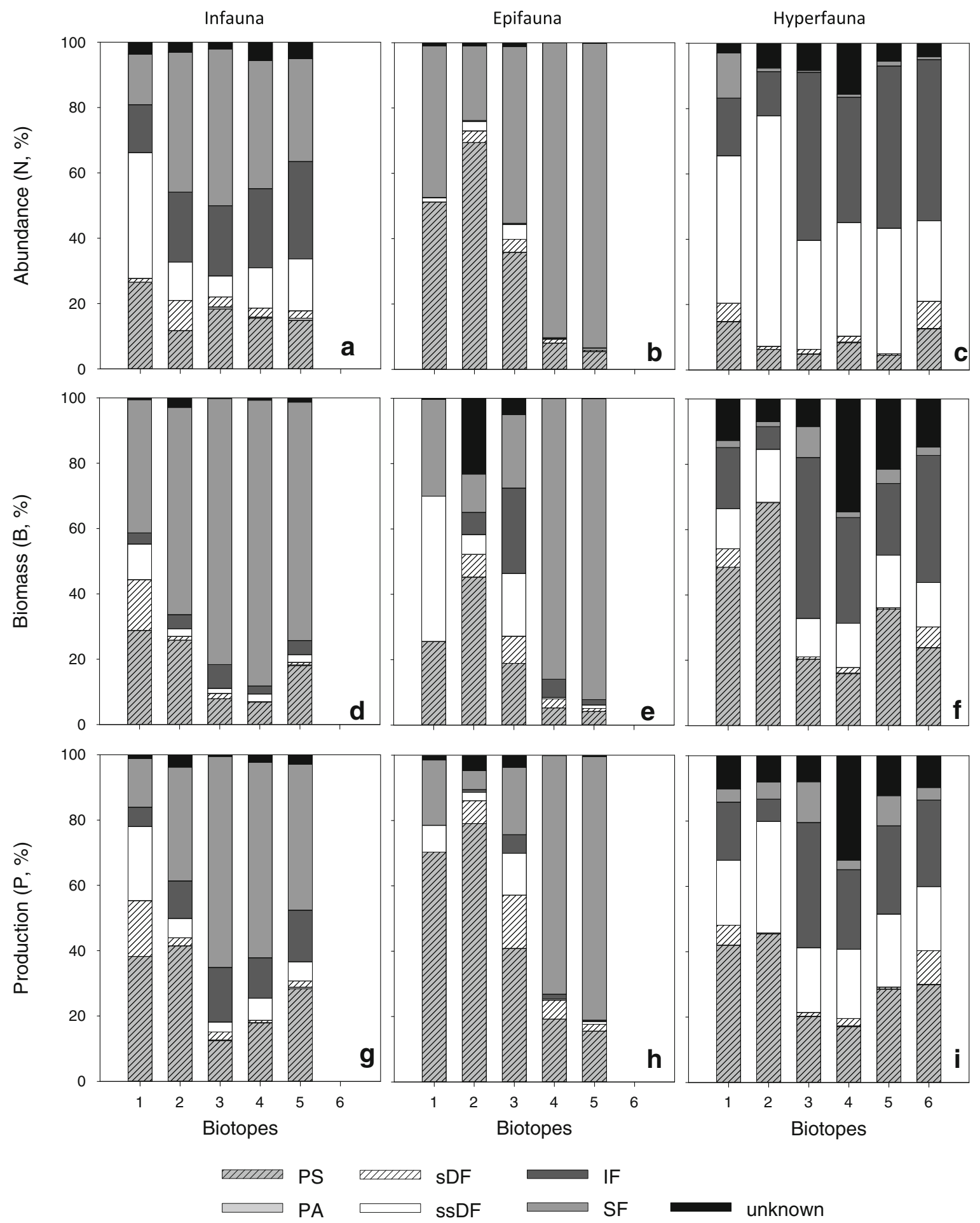

Fig. 16 Feeding-guild proportions (\%) of abundance (a-c), biomass $(\mathbf{d}-\mathbf{f})$ and production $(\mathbf{g}-\mathbf{i})$ of infauna, epifauna and hyperfauna within biotopes (1-6). Feeding guilds: $P A$ predator, active (carnivore); $P S$ predator, scavenger (carnivore); $s D F$ surface deposit feeder; ssDF subsurface deposit feeder; $I F$ interface feeder, i.e. switching between surface deposit feeder and suspension feeder; $S F$ suspension feeder 
not a factor influencing invertebrates but is a proxy for several environmental variables (e.g. temperature, pressure, light level, $\mathrm{O}_{2}$ concentration). In this case, depth reflects the changing temperature regimes in the shallow and deep water areas and the corresponding changes in, e.g. current velocity and food supply. The transition between warm NAW and cold NSDW occurs at a depth of approximately $700 \mathrm{~m}$. This depth represents a major shift in benthic community composition in the Norwegian Sea and has been documented in several studies (e.g. Dahl et al., 1976; BuhlJensen, 1986; Gage, 2001).

Most of the landscapes we defined on the basis of broad-scale seabed morphology have areas (here represented by our video transects) with species compositions not very different from one or more of the other landscapes. This could reflect habitat similarities between landscapes or irrelevant (with respect to faunal grouping) classification of landscapes.

The ambit of a species may change during development. The environmental factors structuring the communities and biotopes operate simultaneously at different spatial scales. This can be exemplified with the hydrodynamic forces which at a broad scale may affect the transport of larvae, at an intermediate scale influence the food concentration, and at a small scale local topography may induce current patterns controlling the distribution of suitable settlement substrates (Doyle, 1975; Pineda, 2000). This may cause one species to be characteristic for habitats and biotopes at different classification levels simultaneously.

Broad-scale habitat or biotope classification is useful background for selecting sub areas to reveal finer spatial patterns of biology, surface geology and topography. More detailed analyses of the seabed substrates and their associated epifauna from the video records together with a wider set of environmental data (currents, bottom temperature, surface primary production, etc.) reveal clearer patterns that can better define marine landscape elements in this area. Mortensen et al. (2009b) and Dolan et al. (2009) have shown that thorough analyses of video results with a finer spatial scale combined with information from multibeam bathymetry enables prediction of habitats at a finer scale with full areal coverage. Such analyses are more suitable for providing background for management decisions, and represent one fundamental outcome from the MAREANO mapping programme. The valuation of habitats largely relies on information about the biodiversity as mentioned above. This information is provided by bottom samples.

\section{Broad scale}

There is a clear indication of fauna groups and habitats relating to the different landscape entities. Particularly banks with coarse substrate and canyons are well defined whilst the intermediate depths of the upper slope constitutes a species rich but less well defined group of biotopes. This is to be expected because the different landscape components (e.g. banks, troughs, canyons) contain several biotopes/habitats that are not unique to the component. Thus, the pattern on this larger scale should be blurred, especially at the depths were the water masses meet and lead to great environmental gradients where representatives of both shallower and deeper biotopes may occur. However, there are certain key species that seem to exclusively connected to certain landscape components, e.g. the octocal Duva florida that often form meadows at slope terraces and the echinoderms Rhizocrinus lofotensis and Hymenaster pellucidus on sandy mud on the lower slope.

Many factors are related to environmental heterogeneity and increase the number of niches available for benthic species. These factors may operate at different scales. In this study we have shown that the species richness is positively correlated with environmental heterogeneity measured as variable composition of sediment grain size (measured as percentage coverage of stones). Our results suggest that a few easily visible key species related to specific communities and bottom types can be used as indicators of biotopes and their associated biodiversity. Experience from fieldwork shows that different habitats cannot always be equally well sampled. It is also obvious that different gear types collect different part of the bottom fauna and that the uniqueness of the fauna sampled is about $70 \%$ for each gear.

Different landscapes and their elements may host a suite of similar habitats with similar species compositions, but when studied at a broader spatial scale combined habitats provide different community "signals" that can be typical for landscapes. There is of course an alternative that the combined habitats "blur" the signal and spatial patterns become less clear. How much this problem affects the broad-scale 
results of this study must be addressed by comparison of fieldwork-based results with detailed post-cruise results from video analyses.

The variation in taxonomic composition associated with this grouping pattern of landscape elements was best correlated with depth, acoustic backscatter and a broad-scale BPI (Fig. 3). Backscatter is a proxy for bottom substrates with generally strong acoustic reflections from hard bottom and weak reflections from soft. However, the backscattering process is complex and is influenced by many physical processes, some of which may be linked with the benthic biology. At Tromsøflaket, backscatter and depth were more strongly; inter correlated than backscatter and observed percentage cover of stones (sum of all gravel sizes). This supports the notion that other factors than bottom types are related with backscatter, e.g. bioturbation, heterogeneity of sediment, and thickness of the surface layer (e.g. Hughes Clarke et al., 1997; Nitsche et al., 2004; Ferrini \& Flood, 2006). One potential factor could be temperature, but this shows little variation within the Tromsøflaket study area. Bottom substrates are likely to have a more pronounced role than the variation in hydrography here and the weak correlation between backscatter and cover of stones may be due to variable acoustic reflectivity by various finer grain sizes than what was possible to discern at the video records (mud and sand were pooled).

Fine scale

The fine scale analysis identified six biotopes in the area 'Tromsøflaket' representing a gradient in habitat heterogeneity with increase in number of bottom types and multibeam backscatter signal from biotope 1 with total cover of soft bottom (99.9\%) to biotope 6 with stones contributing $20 \%$ and sand more than $50 \%$. In parallel with this increase in heterogeneity, a general trend of increase in abundance was found for all fauna groups and a similar pattern was observed for biomass. Both epifauna and infauna showed relatively high biomass in biotopes 4 and 5 whereas infauna also had a high biomass in biotope 3 . In the typical soft bottom biotope, infauna had low biomass and abundance compared to sandy sediments with presence of gravel. The hyperfauna comprising mainly motile crustaceans revealed no clear trend in biomass with regards to the different biotopes. Thus, the fauna groups differed in response to environmental heterogeneity and both epifauna and infauna were more abundant and in higher biomass in biotopes with more heterogeneity indicated by positive correlation with $\%$ gravel and multibeam backscatter and negative correlation to percentage soft bottom and clay. Hyperfauna that consists mainly of motile crustaceans showed a less clear pattern.

Species richness $(S)$ increased for all fauna groups from biotopes 1 to 6 (Fig. 12). For Shannon's $\mathrm{H}^{\prime}$ and evenness $(\mathbf{J})$ the trends are less clear. Epifauna showed decreasing evenness with the increased heterogeneity in biotopes 4 and 5 . Infauna showed an increase in expected number of species (ES) with increased heterogeneity that was not found for epifauna and hyperfauna. Infaunal production was positively correlated with high number of species $(S)$ and higher values of $\mathrm{H}^{\prime}$. For epifauna production was negatively correlated to $H^{\prime}$ and $J$. Production of hyperfauna showed no such correlation.

Composition of functional groups (feeding groups) in biotopes 1 and 2 differed from biotopes 4-6 for all fauna groups, whilst biotope 3 represented a transition. For epifauna and infauna the major change was from dominance of predators in biotopes $1-3$ to a dominance of suspension feeders in biotopes 4-6. However, the major shift occurred between biotopes 2 and 3 for infauna, and between 3 and 4 for epifauna. The difference in composition of functional groups for hyperfauna was less clear but there is a weak trend of more predator/scavengers and less interface feeders in biotopes 1 and 2 relative to biotopes 3-6.

Interestingly epifauna and infauna was most diverse in areas with varied bottom and stronger backscatter signal whilst hyperfauna richness was highest on level bottom with sand.

Both epifauna and infauna are stronger connected to sediment composition due to their lifestyle then the more mobile and swimming hyperfauna. Many shrimps, mysids and amphipods swim about and occasionally sit, walk and bury in or on the sediment surface where they also find their food (mainly detritivores). They are probably dependant on more homogenous and level bottom to find suitable conditions for feeding and searching for food whilst varied bottom structure supply more space for different infauna and epifauna species. Fauna mobility and size affects their ambit (action range, see Jumars, 1975) and thus their response to habitat heterogeneity at different scale. Species with larger ambit encounter 
species and structures in closer approximation to their proportion and thus their environment is coarser 'grained' (MacArthur \& Wilson, 1967) compared to species with small ambit. Thus, fauna components vary in their response to a gradient in habitat diversity (e.g. Klitgaard-Kristensen \& Buhl-Mortensen, 1999).

There are of course sampling biases here because it is not possible to sample with an epibenthic sled in rugged terrain and thus hyperbenthos is not well documented in this kind of habitat. An inherent problem with the data on the three fauna groups is that it is based on different sampling gear that, even though they are normally used in studies of these fauna groups, do not discriminate clearly between epifauna and infauna. I addition the amount of bottom habitat sampled differs substantially between a trawl haul and a grab sample. These are obstacles that are hard to overcome. Furthermore, the functionality of these sampling gears depends on substratum. Bearing this in mind we still believe that the best way to document the relation between habitat heterogeneity and fauna composition is through a wide set of sampling gear that hopefully can provide a more correct picture of the present bottom fauna in a habitat even though the information provides more qualitative than quantitative results and patterns.

\section{Conclusions}

At a broad scale, environmental heterogeneity (number of bottom types) decreases with depth and large scale biotopes connected to landscape elements can be identified.

The most varied environment/landscape elements are fjords and coast and megafauna diversity increases with the environmental heterogeneity. Fauna differences at this scale are most pronounced between the deep lower slope and canyons and shallower shelf areas.

At a fine scale, biotopes with specific environment can be identified within landscape elements. There is a general increase in abundance, diversity, biomass and production of all fauna groups with increased environmental heterogeneity (grain size and terrain ruggedness). However, the fauna groups also reveal a more specific response to environmental differences. Epifauna and infauna diversity increase with hardness of the bottom whilst hyperfauna increase with depth and is negatively correlated with rugosity and clay. Infaunal production and biomass is higher in species rich biotopes whilst epifauna production and biomass is negatively related to diversity but, hyperbenthos reveals no clear pattern. This can be attributed to the looser connection between the bottom substratum and the mobile crustacean fauna of hyperbenthos. With the increased environmental heterogeneity there also seems to be a change in dominating feeding mode from predator/scavenger to suspension feeders.

An important goal for area-based management is to protect marine habitats and their associated fauna, thus, we need to know where the rich and pristine areas are and what they represent of biological value. Our findings reveal environmental patchiness at different scales and that the response of bottom fauna differs with taxonomic group and scale. Thus, it is important to undertake investigations that include all major taxonomic, functional and size related groups. To predict biotopes in new areas with similar environmental setting, we also need to know the scale of the patchiness of fauna, decisive environmental factors or entities. Unfortunately, there is a significant lack of studies that consider multiple spatial scales and species groups within one ecosystem (Tews et al., 2004), but see Williams et al. (2010). Despite the increasing number of publications on MPAs studies devoted to the ecological bases for the establishment and operation of marine reserves are still scarce (Mokievsky, 2009). Baseline mapping for management should include a wide set of fauna components and environmental descriptors to secure a knowledgebased marine spatial management.

Acknowledgments This article is a product of the MAREANO programme (www.mareano.no) financed by the Norwegian government. The authors would like to thank all MAREANO partners, cruise participants, and the crew onboard RV G. O. Sars for their contributions to this study. The authors are indebted to several anonymous reviewers for improving the manuscript.

\section{References}

Babichenko, S., P. Wassmann, L. Poryvkina \& I. Andreassen, 1999. Small time and spatial scale variability of phytoplankton distribution on the north Norwegian shelf in 1995. Sarsia 84: 293-302.

Barnett, V. \& T. Lewis, 1994. Outliers in statistical data, 3rd ed. Wiley, New York. 
Bellec, V., M. F. J. Wilson, R. Bøe, L. Rise, T. Thorsnes, L. Buhl-Mortensen, P. Buhl-Mortensen, 2008. Bottom currents interpreted from iceberg ploughmarks revealed by multibeam data at Tromsøflaket, Barents Sea. Mar Geol 249:257-270.

Berge, J. \& W. Vader, 2001. Revision of the amphipod (Crustacea) family Stegocephalidae. Zoological Journal of the Linnean Society 133(4): 531-592.

Bergman, M. J. N, S. N. R Birchenough, Á. Borja, S. E. Boyd, C. J. Brown, L. Buhl-Mortensen, R. Callaway, D. W. Connor, K. M. Cooper, J. Davieas, I. De Boois, K. D. Gilkinson, D. C. Gordon Jr., H. Hillewaert, H. Kautski, M. De Kluyver, I. Kröncke, D. S. Limpenny, W. J. Meadows, S. Parra, S. E. Pennington, E. Rachor, H. L. Rees, H. Reiss, H. M. Rumohr, Schratzberger, S. Smith, B. G. Tunberg, J. A. Van Dalfsen, S. Ware \& L. Watling, 2009. Guidelines for the study of the epibenthos of subtidal environments. ICES Techniques in Marine Environmental Sciences No. 42. $88 \mathrm{pp}$

Bett, B. J., 2001. UK Atlantic Margin Environmental Survey: introduction and overview of bathyal benthic ecology. Continental Shelf Research 21: 917-956.

Brey T., 2001. Empirical relations in aquatic populations for estimation of production, productivity, mortality, respiration. Population dynamics in benthic invertebrates. A virtual handbook. Version 01.2, http://www.thomas-brey/science/ handbook.

Brey T., 2005. Conversion factors for aquatic organisms. Population dynamics in benthic invertebrates. A virtual handbook. Version 01.2, http://www.thomas-brey/science/ handbook.

Buhl-Jensen, L., 1986. The benthic amphipod fauna of the westNorwegian continental shelf compared with the fauna of five adjacent fjords. Sarsia 71: 193-208.

Buhl-Mortensen, L., 1996. Amphipod fauna along an offshorefjord gradient. Journal of Natural History 30: 23-49.

Buhl-Mortensen, L., A. Vanreusel, A. J. Gooday, L. A. Levin, I. G. Priede, P. Buhl-Mortensen, H. Gheerardyn, N. J. King \& M. Raes, 2010. Biological structures as a source of habitat heterogeneity and biodiversity on the deep ocean margins. Marine Ecology 31(1): 21-50.

Buhl-Mortensen, L., R. Bøe, M. F. J. Dolan, P. Buhl-Mortensen, T. Thorsnes, S. Elvenes \& H. Hodnesdal, 2012. Ch. 51: banks, troughs and canyons on the continental margin off Lofoten, Vesterålen, and Troms, Norway.

Dahl, E., L. Laubier, M. Sibuet \& J.-O. Strömberg, 1976. Some quantitative results on benthic communities of the deep Norwegian Sea. Astarte 9: 61-79.

Davies C. E., D. Moss \& M. O. Hill (2004). EUNIS Habitat Classification Revised 2004. Report to the European Topic Centre on Nature Protection and Biodiversity, European Environment Agency. Available online at http://eunis.eea. eu.int/eunis/habitats.jsp).

Dolan, M. F. J., P. Buhl-Mortensen, T. Thorsnes, L. BuhlMortensen, V. K. Bellec \& R. Bøe, 2009. Developing seabed nature-type maps offshore Norway: initial results from the MAREANO programme. Norwegian Journal of Geology 89: 17-28.

Doyle, R. W., 1975. Settlement of planktonic larvae: a theory of habitat selection in varying environments. American Naturalist 109: 113-126.
Enequist, P., 1949. Studies on the soft-bottom amphipods of the Skagerak. Almqvist \& Wiksells, Uppsala.

Etter, R. J. \& J. F. Grassle, 1992. Patterns of species diversity in the deep sea as a function of sediment particle size diversity. Nature 360: 576-578.

Fauchald, K. \& P. A. Jumars, 1979. The diet of worms: a study of polychaete feeding guilds. Oceanography and Marine Biology: An Annual Review 17: 193-284.

Ferrini, V. L. \& R. D. Flood, 2006. The effects of fine-scale surface roughness and grain size on $300 \mathrm{kHz}$ multibeam backscatter intensity in sandy marine sedimentary environments. Marine Geology 228(1-4): 153-172.

Gage, J. D., 2001. Deep-sea benthic community and environmental impact assessment at the Atlantic Frontier. Continental Shelf Research 21: 957-986.

Golding N., M. A. Vincent \& D. W. Connor, 2004. Irish Sea Pilot - Report on the development of a Marine Landscape classification for the Irish Sea, JNCC. (www.jncc.gov. uk/irishseapilot).

Greene, H. G., M. M. Yoklavich, R. M. Starr, V. M. O'Connell, W. W. Wakefield, D. E. Sullivan, J. E. McRea Jr \& G. M. Cailliet, 1999. A classification scheme for deep seafloor habitats. Oceanologica Acta 22: 663-678.

Hansen, B. \& S. Østerhus, 2000. North Atlantic-Nordic Seas exchanges. Progress in Oceanography 45: 109-208.

Holte, B., 1998. The macrofauna and main functional interactions in the sill basin sediments of the pristine Holandsfjord, northern Norway, with autecological reviews for some key-species. Sarsia 83: 55-68.

Holte B., 2004. The benthic macrofauna in North Norwegian and Svalbard fjord sediments, Troms $\varnothing$.

Holte, B., E. Oug \& S. Cochrane, 2004. Depth-related benthic macrofaunal biodiversity patterns in three undisturbed north Norwegian fjords. Sarsia 89: 91-101.

Hughes Clarke J. E., B. W. Danforth \& P. Valentine, 1997. Areal seabed classification using backscatter angular response at $95 \mathrm{kHz}$. Shallow Water, NATO SACLANTCEN, conference proceedings series CP-45, pp 243-250.

Hurlbert, S. H., 1971. The nonconcept of species diversity: a critique and alternative parameters. Ecology 52: 577-586.

Jumars, P. A., 1975. Environmental grain and polychaete species diversity in a bathyal benthic community. Marine Biology 30: 253-266.

Klitgaard-Kristensen, D. \& L. Buhl-Mortensen, 1999. Benthic foraminifera along an offshore-fjord gradient: a comparison with amphipods and molluscs. Journal of Natural History 33: 317-350.

Lincoln, R. J., 1979. British marine Amphipoda: Gammaridea. British Museum of Natural History, London.

MacArthur, R. H. \& E. O. Wilson, 1967. The Theory of Island Biogeography. Princeton University Press, Princeton: 224 pp.

Magurran, A. E., 2004. Measuring biological diversity. Blackwell Publishing, Oxford.

Mokievsky, V. O., 2009. Marine protected areas: theoretical background for design and operation. Russian Journal of Marine Biology 35(6): 504-514.

Mortensen, P. B. \& L. Buhl-Mortensen, 2005. Coral habitats in the Gully, a submarine canyon off Atlantic Canada. In Freiwald, A. \& J. M. Roberts (eds), Cold-water corals and ecosystems. Springer-Verlag, Berlin, Heidelberg: 247-277. 
Mortensen, P. B., L. Buhl-Mortensen, M. Dolan, J. Dannheim \& K. Kröger, 2009a. Megafaunal diversity associated with marine landscapes of northern Norway: a preliminary assessment. Norwegian Journal of Geology 89: 163-171.

Mortensen P. B., M. F. J. Dolan \& L. Buhl-Mortensen, 2009b. Prediction of habitats on a fishing bank off Northern Norway using a combination of multivariate analysis and GIS classification. ICES Journal of Marine Science. doi: 10.1093/icesjms/fsp200.

Naylor E., 1972. British marine isopods. Keys and notes for the identification of the species. Synopses of the British Fauna N.S. No. 3. Academic Press, New York.

Nitsche, F. O., R. Bell, S. M. Carbotte, W. B. F. Ryan \& R. Flood, 2004. Process-related classification of acoustic data from the Hudson River Estuary. Marine Geology 209(1-4): 131-145.

Pielou, E. C., 1966. The measurement of diversity in different types of biological collections. Journal of Theoretical Biology 13: 131-144.

Pineda, J., 2000. Linking larval settlement to larval transport: assumptions, potentials, and pitfalls. Oceanography of the Eastern Pacific I(2000): 84-105.

Roff, J. C. \& M. E. Taylor, 2000. Viewpoint; National frameworks for marine conservation - a hierarchical geophysical approach. Aquatic Conservation; Marine and Freshwater Ecosystems 10: 209-223.

Rothlisberg, P. C. \& W. G. Pearcy, 1977. An epibenthic sampler used to study the ontogeny of vertical migration of Pandalus jordani (Decapoda, Caridea). Fishery Bulletin, National Oceanic and Atmospheric Administration of the United States 74: 994-997.

Shannon, C. E. \& W. Weaver, 1949. The mathematical theory of communication. University of Illinois Press, Urbana: 117 pp.
Simberloff D. S., 1978. Use of rarefaction and related methods in ecology. In Dickson K. L., J. Cairns Jr. \& R. J. Livingston (eds), Biological Data in Water Pollution Assessment: Quantitative and Statistical Analyses. American Society for Testing and Materials STP 652, Philadelphia: 150-165.

Soetaert, K. \& C. Heip, 1990. Sample-size dependence of diversity indices and the determination of sufficient sample size in a high-diversity deep-sea environment. Marine Ecology Progress Series 59: 305-307.

Tews, J., U. Brose, V. Grimm, K. Tielbörger, M. C. Wichmann, M. Schwager \& F. Jeltsch, 2004. Animal species diversity driven by habitat heterogeneity/diversity: the importance of keystone structures. Journal of Biogeography 31: 79-92.

Thorsnes, T., L. Erikstad, M. F. J. Dolan \& V. K. Bellec, 2009. Submarine landscapes along the Lofoten-VesterålenSenja margin, northern Norway. Norwegian Journal of Geology 89: 5-16.

Wentworth, C. K., 1922. A scale of grade and class terms for clastic sediments. Journal of Geology 30: 377-392.

Whittaker, R. J., K. J. Willis \& R. Field, 2001. Scale and species richness: towards a general hierarchical theory of species diversity. Journal of Biogeography 28: 453-470.

Williams, A. et al., 2010. Scales of habitat heterogeneity and megabenthos biodiversity on an extensive Australian continental margin (100-1000 m depths). Marine Ecology 31: 222-236.

Wilson, M. F. J., B. O' Connell, C. Brown, J. C. Guinan \& A. J. Grehan, 2007. Multiscale terrain analysis of multibeam bathymetry data for habitat mapping on the continental slope. Marine Geodesy 30: 3-35. 